NBER WORKING PAPER SERIES

\title{
A WELFARE ANALYSIS OF COMPETITIVE INSURANCE MARKETS WITH VERTICAL DIFFERENTIATION AND ADVERSE SELECTION
}

\author{
W. Bentley MacLeod \\ Working Paper 28565 \\ http://www.nber.org/papers/w28565 \\ NATIONAL BUREAU OF ECONOMIC RESEARCH \\ 1050 Massachusetts Avenue \\ Cambridge, MA 02138 \\ March 2021
}

This paper evolved from a set of comments on Geruso et al. (2019) for the NBER Health Conference, Lugano, Switzerland, June 2019. I would 1 like to thank Jon Skinner for inviting me to participate and to Janet Currie, Kate Ho, Tim Layton, Michael Geruso, Mark Shepard, Ashley Swanson and the Princeton IO/Health seminar for helpful comments and discussions. Thomas Braun, Utkarsh Kumar, Suneil Parimoo and Roman Rivera provided helpful research assistance on this project. There are no sources of external funding for this research. The views expressed herein are those of the author and do not necessarily reflect the views of the National Bureau of Economic Research.

NBER working papers are circulated for discussion and comment purposes. They have not been peer-reviewed or been subject to the review by the NBER Board of Directors that accompanies official NBER publications.

(C) 2021 by W. Bentley MacLeod. All rights reserved. Short sections of text, not to exceed two paragraphs, may be quoted without explicit permission provided that full credit, including () notice, is given to the source. 
A Welfare Analysis of Competitive Insurance Markets with Vertical Differentiation and Adverse Selection

W. Bentley MacLeod

NBER Working Paper No. 28565

March 2021

JEL No. D01,D21,D41,I11,I13,L15

\begin{abstract}
A feature of many insurance markets is that they combine vertical differentiation (all consumers prefer high to low-coverage policies) and adverse selection (high cost customers prefer highcoverage plans). Building on Novshek and Sonnenschein (1978) and Azevedo and Gottlieb (2017), this paper characterizes the competitive equilibria in a vertically differentiated market characterized by adverse selection. This provides a simple, dynamic model of the market, along with their welfare consequences over time in response to policy changes. The model makes predictions consistent with recent evidence on the ACA exchange in the US (Frean et al. (2017)). Moreover, it provides a complete characterization of the health insurance "death spiral". The death spiral leads to an inefficient outcome, but does not lead to a complete breakdown of the market. Rather, it predicts a large number of plans, with coverage that falls with an individual's willingness to pay. It is shown that introducing a minimum coverage standard combined with an insurance mandate cannot restore efficiency. The optimal system depends on both the valuation of public funds and the social value of insurance. Depending on these parameters, a number of different types of systems may be optimal, including a single payer system with mandatory participation for all, such as the Canadian system, a mixed private-public system, as one sees in many countries, or a pure, free market system.
\end{abstract}

\author{
W. Bentley MacLeod \\ Department of Economics \\ Columbia University \\ 420 West 118th Street, MC 3308 \\ New York, NY 10027 \\ and NBER \\ wbmacleod@wbmacleod.net
}

A data appendix is available at http://www.nber.org/data-appendix/w28565 


\section{INTRODUCTION}

Healthcare markets in the United States are one of the most complex and intensely studied markets in economics. They are characterized by a number of market failures, particularly adverse selection and moral hazard, that in turn make it difficult to assess appropriate policy interventions. The recent literature has focused on how existing policy instruments can bring about marginal improvements in performance. This leaves open the question of what would an optimal market structure look like? This paper addresses this question using a stylized dynamic model of a competitive market with adverse selection. The dynamics not only provide a method to compute the equilibria, they also sign the comparative static effect of policy changes. Using this framework one can compare a variety of market structures, including a free-entry equilibrium that captures the well known "death spiral" (Cutler and Reber (1998)), a minimum coverage standard, a tax mandate, a public system, and a mixed market/public system. A feature of the welfare analysis is that the perceived costs of public funds is allowed to vary. Depending on one's attitudes toward public expenditures, the optimal system varies between a pure single payer public supplier system and a mixed market/public system.

Geruso and Layton (2017) observe that there are two distinct approaches to the study of markets with adverse selection, depending upon whether contracts are fixed or endogenous. The fixed contracts approach typically assumes that there are one or two choices available to consumers. The benefit of this approach is that it can easily be confronted with data. Einav et al. (2010) use the single contract case to study the welfare impact of inefficient price policies on welfare. Handel et al. (2015) use Handel (2013) to extend Einav et al. (2010) to the case of two contracts, with prices determined by the Riley (1979) equilibrium concept. They find that adverse selection may lead to full unraveling of the market, as Cutler and Reber (1998) found for the Harvard health plan. Geruso et al. (2019) also study a two contract model to estimate the differential effects of regulation on the extensive margin (decision to buy insurance) and the intensive margin (the choice between a high-coverage and low-coverage plan).

The endogenous contracts approach builds upon the work of Akerlof (1970) and Rothschild and Stiglitz (1976). Their results are largely negative - in many cases adverse selection leads to the non-existence of an equilibrium and market failure. Azevedo and Gottlieb (2017) show that one may solve this problem with a perfectly competitive model with free entry of products that allows for some "behavioral types". The competitive equilibrium is given by the limit of a behavioral equilibrium as the number of behavioral types approaches zero. They prove the existence of an equilibrium and show that they are able to calibrate their model to estimate the effect of an insurance mandate. However, they did not do an extensive welfare analysis of alternative market structures. ${ }^{1}$

The next section outlines a welfare analysis of a two consumer type model with endogenous entry of products with different coverage levels. This illustrates how allowing product entry can ensure the existence of an equilibrium at which all types are served. The results of this section are later contrasted with the results with a continuum of consumer types to illustrate the role that the distribution of consumer characteristics plays in determining the appropriate policy intervention. A

\footnotetext{
${ }^{1}$ Azevedo and Gottlieb (2017) suggest that this is a question for future research.
} 
dynamic formulation of the equilibrium is introduced. This approach solves the existence problem because existence depends upon the solution to a differential equation, that are known to exist for a wide set of conditions. ${ }^{2}$ Empirically, such an approach also generates predictions on how the system adjusts in real time to shocks.

Sections 2-5 use the revelation principle from mechanism design theory to build a dynamic competitive model with adverse selection (Myerson (1979)). A difficulty with the original Rothschild and Stiglitz (1976) model is that it is non-linear, making it very difficult to generalize. In this paper, a linear model with vertically differentiated produces is introduced, along the lines of Gabszewicz and Thisse (1979). This allows one focus upon the effects that adverse selection has on market equilibria, and also allows for a closed form solution to the model. Finally, it is shown, via the revelation principle, that one can move between price and quantity representations of the market allocation.

Section 6 uses these ideas to illustrate the two-margin issue that has been explored in the health economics literature (Geruso et al. (2019)). Section 7 extends the model to allow for the free entry of products with different qualities. It is shown that an equilibrium exists that is characterized by a large number of different quality products, with low valuation consumers choosing low quality products. At this equilibrium all consumer types are served, but the outcome is Pareto inefficient.

Sections 8 and 9 study interventions that might enhance efficiency. Section 8 looks at the effect of minimum quality standards and an insurance mandate (a penalty for not purchasing insurance), a widely used solution to the adverse selection problem. It is shown to be dominated by the free entry equilibria. Section 9 allows for government subsidies. The size of these subsidies depends upon the dead-weight cost of raising government revenue. When the costs of revenue collection are low, the optimal system is a pure public system. An unregulated free-entry system is optimal when the cost of government funds is very high.

These solutions are derived based upon measured consumer surplus, and hence ignores negative externalities that arise from having low levels of health care for low income individuals. Section 10 solves for the optimal subsidy levels when one incorporates this negative externality into the objective function. It is shown that with pure vertical differentiation, it is optimal to have a single high quality plan that is available to all consumers. The quality of the plan is a function of the cost of public funds, and the social value that is associated with the provision of health care to all. The final section discusses shortcomings and possible extensions of this model.

\section{A Two Type Example}

The main analysis in the paper assumes that there are a continuum of consumer types that leads to smooth, downward sloping demand curves, and is standard in this literature. The innovation is to allow for a continuum of quality levels. Before going to the full analysis, this section outlines the implications of a continuum of coverage levels in a simple, two consumer type framework. In addition to illustrating how the market works with free entry of products, it highlights the role that

${ }^{2}$ See MacLeod (1985) for a discussion of how the introduction of dynamics and adjustment costs provide a method for equilibrium selection. On existence see Hirsch and Smale (1974). 
the distribution of costs play for both the analysis of the equilibria, and the welfare properties of alternative systems.

Suppose that there are two consumer types, $t \in\{H, L\}$, corresponding to high and low demand for care. With full coverage, the willingness to pay and cost are given by $v_{t}$ and $c_{t}$ respectively, that satisfy:

$$
v_{H}>c_{H}>v_{L}>c_{L}>0 .
$$

The product coverage for consumer $t \in\{H, L\}$ is given by $\alpha_{t} \in[0,1]$. Let $p_{t}$ be the price paid by consumer $t$. The willingness to pay for this product is $\alpha_{t} v_{t}$, while the cost of serving this consumer is $\alpha_{t} c_{t}$. The revelation principle is used to solve for the equilibrium by describing the allocation in terms of consumer types, and then adding the appropriate self-selection constraints for the products destined to consumers $t \in\{H, L\}$. The utility of consumer $t$ who buys product $\hat{t}$ is:

$$
u(t, \hat{t})=\alpha_{\hat{t}} v_{t}-p_{\hat{t}} .
$$

The revelation principle implies that feasible allocations must satisfy the self-selection constraints:

$$
u(t, t) \geq u(t, \hat{t}), \forall t, \hat{t} \in\{H, L\} .
$$

It is assumed that the market is perfectly competitive, though the government can regulate the products offered to the market and can subsidize firms that are earning negative profits. There are two parameters that can vary, the fraction of high willingness to pay consumers, $\rho \in[0,1]$, and the marginal welfare cost of subsidies, given by $\lambda \geq 0$. The next subsection computes the competitive equilibrium, followed by a derivation of optimal policy.

Competitive Equilibrium. Consider first the necessary conditions for a separating equilibrium each type gets a different product. In this model it is always efficient for all consumers to purchase high-coverage. The single-crossing condition implies that the high willingness to pay consumers must be assigned to the quality at least as good as the low willingness to pay consumers, thus let us set $\alpha_{H} \equiv 1$, the highest possible value. At a separating equilibrium the low types purchase $\alpha_{L}<1$. The profits of the firms serving type $t \in\{H, L\}$ are:

$$
\pi_{i}=\rho_{i} \alpha_{i}\left(p_{i}-c_{i}\right),
$$

where $\rho_{H}=\rho$ and $\rho_{L}=(1-\rho)$. In equilibrium firms earn zero profits. The government may wish to subsidize firms providing quality $\alpha_{i}$ in the market with subsidy $s_{i}$, in which case the free entry equilibrium is given by:

$$
\pi_{i}+\rho_{i} s_{i}=0,
$$

and the social cost of this subsidy is $\lambda \rho_{i} s_{i}=-\lambda \pi_{i}$. Initially we work out the competitive equilibrium with $s_{i}=0$.

The price, $p_{H}(\alpha)$, at which a high type is indifferent between $\alpha_{H}=1$ and buying a product $\alpha$ is:

$$
\begin{aligned}
\alpha v_{H}-p_{H}(\alpha) & =v_{H}-c_{H}, \\
p_{H}(\alpha) & =c_{H}-(1-\alpha) v_{H} .
\end{aligned}
$$


The break even price for low willingness to pay consumers who buy product $\alpha$ is $p_{L}(\alpha)=\alpha c_{L}$. At a competitive equilibrium it must be the case that each type self-selects into their respective markets. Thus, if the low quality firm chooses to supply $\alpha_{L}$, the price is set to cover costs, and not attract customers from the high quality firm. Hence price must satisfy:

$$
p\left(\alpha_{L}\right)=\max \left\{p_{H}\left(\alpha_{L}\right), p_{L}\left(\alpha_{L}\right)\right\} .
$$

Competition forces firm $L$ to zero profits, and hence the equilibrium quality, $\alpha_{L}^{*}$, must satisfy:

$$
p_{H}\left(\alpha_{L}^{*}\right)=p_{L}\left(\alpha_{L}^{*}\right)
$$

This ensures that low willingness to pay consumers buy $\alpha_{L}^{*}$, while high willingness to pay consumers are indifferent between any product $\alpha \in\left[\alpha_{L}, 1\right]$, and hence choosing $\alpha_{H}=1$ is optimal. Notice, that under the belief that only high cost customers buy products in $\left(\alpha_{L}, 1\right)$, firms would earn negative profits (see equation 3), and hence it is not profitable to enter with a product $\alpha \in\left(\alpha_{L}, 1\right)$. For $\alpha \in\left[0, \alpha_{L}\right]$ firms believe only low cost consumers would choose such a product, and hence profits are zero.

At this allocation, firms earn zero profits and consumers are choosing their most preferred product. This is illustrated in figure 1 . The equilibrium price is indicated by the heavy dashed line that corresponds to expression (4). Observe that the payoff of the low type is maximized at $\alpha=\alpha_{L}$. The high type's self-selection constraint is binding, hence her payoff is constant from $\alpha_{L}$ to $\alpha_{H}=1$.

In the formal competitive model that is outlined below, where firms set quantities, this is a stable competitive equilibrium. It is not efficient because it is a Pareto improvement to increase product quality for the low willingness to pay individuals. It is important to emphasize that the competitive equilibrium here does not depend upon the distribution of consumer types - a result that is generalized in section 7 to a continuum of types. This means that in an adverse selection contexts the incentive constraints, rather than supply/demand factors, are the main determinants of price. Thus, it is not surprising that adverse selection leads to inefficient outcomes.

Policy Choices. In this example it is possible for government intervention to enhance welfare. Notice that at the competitive equilibrium all types are purchasing insurance, and hence an insurance mandate - requiring the uninsured to purchase insurance - would have no effect. This result is generalized in section 7 to provide a theoretical explanation of why changes in the insurance mandate have a small effect on insurance take-up in the market (Frean et al. (2017)). The problem of uninsured individuals is addressed separately in section 10.

The government can enhance performance with two instruments - control of product coverage and the use of subsidies, or what is more commonly known as risk adjusted prices (see Layton (2017)). The choice of instruments depends upon the distribution of individuals between high and low types. Define $\rho^{0} \in(0,1)$ as the fraction of high types that makes the low type indifferent between consuming product $\alpha_{H} \equiv 1$ and no insurance:

$$
v_{L}=\underset{5}{A C}\left(\rho^{0}\right)
$$




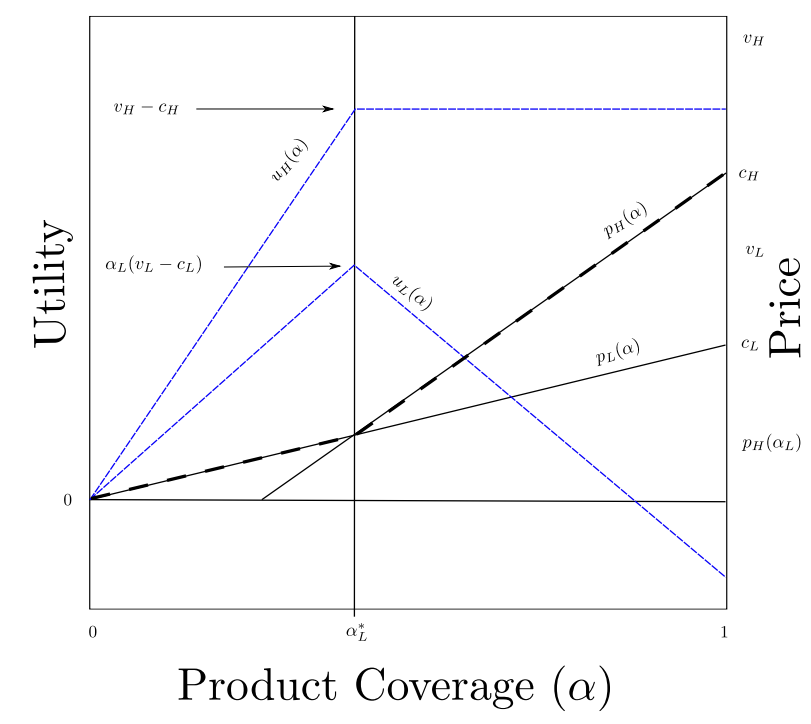

FIgure 1. Competitive Separating Equilibrium

where

$$
A C(\rho)=\rho c_{H}+(1-\rho) c_{L},
$$

is the average cost of providing product $\alpha_{H}$ to both types of consumers, given the fraction of high types, $\rho$.

When $\rho<\rho^{0}$ then the average cost of supplying all types is lower than $v_{L}$. Hence, if product $\alpha_{H}$ is priced at $p_{1}=A C(\rho)$, all consumers would choose $\alpha_{H}$ at that average cost price. This would give an efficient allocation. The problem is that with free entry the equilibrium is not stable. Firms can enter with a product $\alpha<1$ that is priced so that the low types prefer it to $\alpha_{H}$, but the high types do not. ${ }^{3}$ This is the so called "death spiral" effect discussed in the introduction. In this particular case, the policy intervention is simple: set the minimum coverage standard to be $\alpha_{H}=1$, and then let market forces set the price.

This solution is not feasible when the value of willingness to pay of the low type is less than average costs $\left(v_{L}<A C(\rho)\right)$. In that case, even with a minimum quality standard, low types will exit the market, forcing prices up to the cost of the high willingness to pay and leaving the low types uninsured. Notice, that in this case, the low types would strictly prefer the free market solution since they would get positive as opposed to zero utility without a coverage standard. It is shown in section 8 that in general a minimum quality standard is not efficient for this reason.

A solution to this problem is to subsidize the purchase of the high quality insurance. Given $\rho \geq \rho^{0}$, the level of subsidy is the amount that would leave the low type indifferent between coverage $\alpha_{H}$

\footnotetext{
${ }^{3} \mathrm{~A}$ firm can enter with product $\left\{\alpha_{L}, p_{L}=\alpha_{L} c_{L}\right\}$ that is attractive to the low cost consumer, but would not be chosen by the high cost consumer:

$$
\alpha_{L}\left(v_{L}-c_{L}\right)>v_{L}-A C(\rho)
$$$$
v_{H}-A C(\rho)>\alpha_{L}\left(v_{H}-c_{L}\right) \text {. }
$$

The existence of such an $\alpha_{L}$ follows from the fact that $\frac{v_{L}-A C(\rho)}{v_{L}-c_{L}}>\frac{v_{H}-A C(\rho)}{v_{H}-c_{L}}$. 


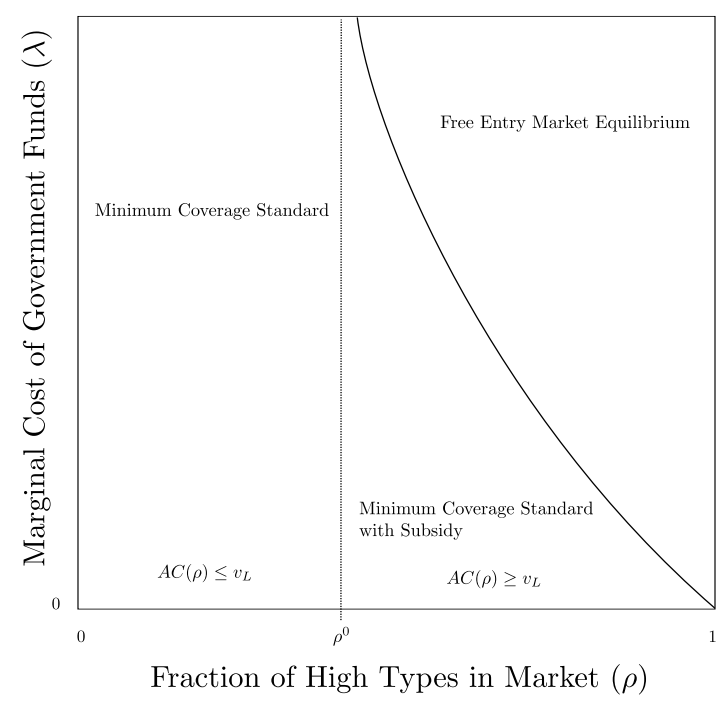

Figure 2. Optimal Market Regulation

and no coverage:

$$
s(\rho)=A C(\rho)-v_{L} .
$$

Since types are not observed, the subsidy has to be paid to all types (normalized to 1 ), and hence total subsidy is $s(\rho)$, with a social cost of $\lambda s(\rho)$.

We can put this all together and consider the welfare consequence of two options - a free market and the optimal subsidy that results in all consumers being covered. Under the free market solution welfare is:

$$
W^{M}(\rho)=\rho\left(v_{H}-c_{H}\right)+(1-\rho) \alpha_{L}^{*}\left(v_{L}-c_{L}\right),
$$

where $\alpha_{L}^{*}$ is given by (5). Under the minimum coverage standard plus subsidy, one has:

$$
\begin{aligned}
W^{G}(\rho, \lambda) & =\rho\left(v_{H}-c_{H}\right)+(1-\rho)\left(v_{L}-c_{L}\right) \\
& -\lambda\left(\min \left\{0, A C(\rho)-v_{L}\right\}\right) .
\end{aligned}
$$

The second line is the welfare cost of the subsidy when average costs are greater than the low type's valuation and thus includes the case in which $\rho<\rho^{0}$. The choice of system depends upon which is greater, $W^{M}$ or $W^{G}$. When average costs are less than the low type's valuation then a minimum standard is efficient, and solves the adverse selection problem. When this is not the case, then the choice depends upon the dead weight losses due to the subsidy. When the cost of funds, $\lambda$, is large, then a free market solution may be preferred. These trade-offs are illustrated in figure 2 .

This figure illustrates the three interventions that are considered in this paper. The first is the benchmark free market equilibrium. When the cost of government intervention is high and average cost of full coverage is higher than the valuation of the lowest willingness to pay consumer, then this may be optimal.

When the average cost of full coverage is less than the willingness to pay of all market participants, then the only intervention necessary is to place a lower bound on the level of coverage - this stops 
the entry of firms who cream skim the low cost consumers. This is illustrated in the region where the fraction of high cost types is sufficiently low $\left(\rho<\rho^{0}\right)$.

Finally, in the case when the average cost of full coverage is greater than the willingness to pay of the low valuation consumer, and $\lambda$, the marginal cost of public funds is sufficiently low, then a system with subsidized insurance is optimal. This is the region below the curved line with the fraction of high types $\rho \in(0,1)$.

One might wonder if one could achieve this outcome "free of charge" with an insurance mandate. In that case, rather than pay a subsidy, one could require individuals to pay a fee equal to the subsidy if they buy no insurance, in which case the low value consumers would choose purchase insurance rather that remain uninsured.

There are a number of issues here. First, in this example there are only two types, and hence setting the mandate is straight forward. When there is a continuum of types, then for any positive cost of funds it will be the case that some consumers will be un-served. Hence there are tradeoffs that depend upon the distribution of costs, and how one values the tax revenues collected via the mandate. It may also be the case that the willingness to pay may not in fact be an accurate representation of the private returns to insurance, a case that is considered section 10 .

\section{Preliminaries and Type Normalization}

This section generalizes the example to a continuum of consumer types.

3.1. Type Normalization and Monotonicity. Consider a market with a full coverage insurance product that is sold to consumers who are assumed to have types given by $s \in S \subset \Re^{n}$, where $S$ is a compact set, whose willingness to pay and cost of the product are given by continuous and differentiable functions $v_{s}(s), c_{s}(s) \geq 0$. Let $g(s)>0$ be a bounded, piece-wise continuous probability density function for types, with $\int_{s \in S} g(s) d s=1$. Theses types can be quite general, and may measure risk aversion or moral hazard effects. The model can be simplified with some relatively mild conditions:

(1) Types $\bar{s} \in \bar{S}$ do not get ill: $v_{s}(\bar{s})=c_{s}(\bar{s})=0$, and $\bar{S} \neq \emptyset$ has measure zero.

(2) All types have a willingness to pay greater than costs: $v_{s}(s)>c_{s}(s)>0, \forall s \in S \backslash \bar{S}$.

The first assumption is that there is a small number of individuals who never fall ill, an assumption that can be relaxed at the cost making the analysis more complex. The second assumption is that individuals all benefit from insurance. Next define:

$$
c_{v}(v)=E\left\{c_{s}(s) \mid v_{s}(s)=v, s \in S\right\} .
$$

Since $v_{s}()$ and $c_{s}()$ are differentiable functions and there is full support, this function is well defined. Let $\bar{v}=\max _{s \in S} v_{s}(s)$ be the maximum benefit. Without loss of generality we can scale costs (choose the currency) such that $\max _{v \in[0, \bar{v}]} c_{v}(v)=1$. Thus the function $c_{v}(v)$ maps from consumer benefit onto the expected costs. From condition (2) it also follows:

$$
c_{v}(v) \leq E\left\{v \mid v_{s}(s)=v, s \in S\right\}=v .
$$


Following Einav et al. (2010) and Geruso et al. (2019), it is assumed that high types are those with low costs. This allows one to illustrate curves corresponding to upward sloping supply and downward sloping demand curves. A consumer of type $t$ corresponding to willingness to pay $v$ is defined by:

$$
t(v)=1-c_{v}(v) .
$$

It is assumed that the high type (lower cost) consumers get less benefit from insurance:

Definition 1. The market is smooth and monotonic if, for all $v \in[0, \bar{v}]$, there is a $m<0$ such that $\frac{d t(v)}{d v}$ is continuous and $\frac{d t(v)}{d v} \leq m$.

Under this assumption we can now parameterize types by a characteristic that is potentially observable ex post: the expected cost of service. Moreover, since costs are strictly monotonic in type, then this function is invertible, and the willingness to pay as a function of type $t$ is given by:

$$
v(t) \equiv c_{v}^{-1}(1-t) \geq(1-t),
$$

where $(1-t) \in[0,1]$ is the expected cost of service, and the inequality follows from (6). Under this parameterization $v(0)=\bar{v}$ and $v(1)=0$. The cumulative distribution of costs is given by:

$$
F(t) \equiv \operatorname{Prob}[v(s) \geq v(t)]=\int_{s \in\{s \mid v(s) \geq v(t), s \in S\}} g(s) d s,
$$

and the density function is $f(t)=F^{\prime}(t)$. In the standard adverse selection model types are an abstraction. This re-normalization shows that when expected customer costs are monotonically related to willingness to pay, then we can use expected cost to define types. It is assumed that the firms cannot observe expected costs nor benefits ex ante. It is useful to extend $F(t)$ to $\Re_{+}$and thus let $F(t)=1, t \geq 1$.

Thus, the primitives of the market can be described by two functions. The first, is the distribution of costs across the population, given by $f(t)>0$. It is well known that multiple competitive equilibria are possible in markets with adverse selection. We shall see that multiple equilibria may arise when the distribution of types is non-monotonic. The second ingredient is the welfare gain from trade, defined by $w(t) \geq 0, t \in[0,1]$. It is assumed that this is a differentiable and strictly decreasing function, where $w(1)=0$. The consumer $t^{\prime} s$ willingness to pay for full coverage, $v(t)$, is therefore:

$$
v(t)=w(t)+(1-t)
$$

The benefit of this definition is that our analysis admits any positive and strictly decreasing function $w^{\prime}(t)<0, t \in[0,1)$. Notice that $w(0)=\bar{v}-1$. In the subsequent analysis the functions $w(t)$ and $v(t)$ are used interchangeably, depending on which function provides the most elegant expression.

3.2. Vertical Differentiation. It is a feature of the American ACA exchanges for health insurance that product differentiation is vertical. Under a "bronze" plan consumers pay less, but also get less benefit than under a "silver" plan, and so on for "gold" and "platinum" plans. Plans are parameterized by their coverage levels, given by $\alpha_{i} \in[0,1]$, and indexed by $i \in\{1, \ldots, n\}$ As a matter of convention, 
the best, full coverage, plan is given by $i=1$ and $\alpha_{1}=1$. It is assumed there are $n$ plans, indexed by $i=1, \ldots, n$, with coverage level $\alpha_{i}$, such that $\alpha_{i}>\alpha_{i+1} \geq 0$. The welfare gain and cost for consumer $t$ is given by:

$$
\begin{aligned}
& w\left(t, \alpha_{i}\right)=\alpha_{i} \times w(t), \\
& c\left(t, \alpha_{i}\right)=\alpha_{i} \times(1-t) .
\end{aligned}
$$

This implies that the willingness to pay is:

$$
\begin{aligned}
v\left(t, \alpha_{i}\right) & =\alpha_{i} w(t)+\alpha_{i} c(t) \\
& =\alpha_{i} v(t)
\end{aligned}
$$

It is assumed that the outside option for products is zero and the vector of products available to the market is given by:

$$
\vec{\alpha}=\left\{\alpha_{1}=1, \alpha_{2}, \ldots, \alpha_{n}\right\},
$$

The market has 1 high-coverage (full insurance) product that is preferred by all consumers, and $n-1 \geq 0$ lower coverage products.

\section{Demand: The Revelation Principle and Product Choice}

This section uses the revelation principle to fully characterize allocations in terms of the quantity choice for each product type. In contrast to the use of prices, this ensures that payoffs are continuous in quantities, which in turn allows for the definition and computation of a stable competitive equilibrium.

4.1. Prices and Customer Demand. Let $\vec{p}=\left\{p_{1}, \ldots, p_{n}\right\}$ be the vector of prices for each product. Since there is vertical differentiation then consumers would never purchase product $\alpha_{i}<\alpha_{j}$ if $p_{i} \geq p_{j}$, and thus prices can be required to satisfy $p_{i} \geq p_{j}$ for all $j \geq i$. Let the set of possible contracts be denoted by $\kappa=\{\vec{p}, \vec{\alpha}\} \in K \subset \Re_{+}^{n} \times[0,1]^{n}$, where $\alpha_{i}>\alpha_{i+1}$ and $p_{i} \geq p_{i+1}, i=1, \ldots, n$. The payoff of a customer of type $t$ from buying product $i$ is given by:

$$
u\left(p_{i}, \alpha_{i} \mid t\right)=\alpha_{i} v(t)-p_{i}
$$

Insurance companies cannot directly observe costs $e x$ ante, and hence for a given product $\alpha_{i}$ all customers pay the same price. Consider two products, $\alpha_{i}>\alpha_{j}$ selling at prices $p_{i}$ and $p_{j}$. Further suppose that both products have positive demand. This in turn implies that there is $t_{i}$ and $t_{j}$ such that $\alpha_{i} v\left(t_{i}\right)-p_{i}>\alpha_{j} v\left(t_{i}\right)-p_{i}$ and $\alpha_{i} v\left(t_{j}\right)-p_{j}<\alpha_{j} v\left(t_{j}\right)-p_{j}$, which in turn implies a $t_{i j}$ such that:

$$
\begin{gathered}
\alpha_{i} v\left(t_{i j}\right)-p_{i}=\alpha_{j} v\left(t_{i j}\right)-p_{j}, \\
\left(\alpha_{i}-\alpha_{j}\right) v\left(t_{i j}\right)=p_{i}-p_{j},
\end{gathered}
$$

Since the payoff is decreasing with $t$ this implies that demand satisfies the single crossing property and we have that customers with $t>t_{i j}$ prefer the lower coverage product $\alpha_{j}$, while customers with $t<t_{i j}$ prefer the higher coverage product $\alpha_{i}$. Given that customers self-select into insurance 
products this implies that given a set of products, $\vec{\alpha}$, sold at price $\vec{p}$, then it must be the case that the allocation of contracts to customers can be given by the vector:

$$
\vec{t}=\left\{t_{1}, \ldots, t_{n}\right\} \in \Gamma,
$$

where $0 \leq t_{1} \leq \ldots \leq t_{n-1} \leq t_{n} \leq 1$ and $\Gamma \subset \Re_{+}^{n}$ denotes the set of feasible types. Let $\Gamma^{0}$ denote the interior where $t_{i}>t_{i+1}$ for $i=1, \ldots, n$, where as a matter of convention set $t_{0}=0$ (the consumer with the highest willingness to pay) and $t_{n+1}=1$. The consumers who buy only product $\alpha_{i}$ are given by interval $\left(t_{i-1}, t_{i}\right)$. Consumers in $\left(t_{n}, t_{n+1}=1\right)$ do not buy insurance (or equivalently $\alpha_{n+1}=0$ ). As a matter of convention, if product i has no demand, set $t_{i-1}=t_{i}$. Thus, given any price vector $\vec{p}$ this results in a well-defined partition of consumers who are allocated to one of the insurance contracts. ${ }^{4}$ Given $\kappa=\{\vec{p}, \vec{\alpha}\}$, let $\vec{t}(\kappa) \in \Gamma$ denote this partition. Notice that $\Gamma$ is a compact, convex set.

Consider the converse problem. Given a partition $\vec{t} \in \Gamma$, what are prices for the products that result in types in $\left(t_{i-i}, t_{i}\right)$ choosing product $\alpha_{i}$ ? These prices can be derived recursively. For the consumer of type $t_{n}$ the product must be priced to make her indifferent between no insurance and purchasing insurance of coverage $\alpha_{n}>0$ :

$$
\begin{aligned}
\alpha_{n} v\left(t_{n}\right)-p_{n} & =p_{n+1}=0, \\
p_{n} & =\alpha_{n} v\left(t_{n}\right) .
\end{aligned}
$$

The single crossing property ensures that only types $t>t_{n}$ do not buy insurance. Next consider a customer with type $t_{i}, i<n$. In that case the customer has to be indifferent between $\alpha_{i}$ and $\alpha_{i-1}$ :

$$
\begin{aligned}
\alpha_{i} v\left(t_{i}\right)-p_{i} & =\alpha_{i+1} v\left(t_{i}\right)-p_{i+1} . \\
p_{i} & =\left(\alpha_{i}-\alpha_{i+1}\right) v\left(t_{i}\right)+p_{i+1} \\
& =\delta_{i} v\left(t_{i}\right)+p_{i+1}
\end{aligned}
$$

where $\delta_{i} \equiv \alpha_{i}-\alpha_{i+1}>0, i=0,1, . ., n$.

There can be some price indeterminacy if a good is not supplied to the market. For example, suppose that $t_{i-1}=t_{i}$. In that case product $\alpha_{i}$ does not affect the relative price between product $\alpha_{i+1}$ and $\alpha_{i-1}$ and we have:

$$
p_{i-1}=\left(\alpha_{i-1}-\alpha_{i+1}\right) v\left(t_{i-1}\right)+p_{i+1} .
$$

The price of product $\alpha_{i}$ simply has to have the feature that no customer wishes to purchase the good:

$$
\alpha_{i} v\left(t_{i}\right)-p_{i} \leq \alpha_{i+1} v\left(t_{i}\right)-p_{i+1}=\alpha_{i-1} v\left(t_{i}\right)-p_{i-1} .
$$

Without loss of generality, whenever $t_{i}=t_{i-1}$, the price $p_{i}$ is set to satisfy (11) with equality. This in turn implies that (10) can be used for all prices, even for those products with zero demand. This discussion implies the following proposition:

\footnotetext{
${ }^{4}$ At the boundaries consumers are indifferent between the two products on sold on each side of the boundery. However, they are a set of measure zero and do not affect neither prices nor demand.
} 
Proposition 2. For any set of contracts $\kappa=\{\vec{p}, \vec{\alpha}\} \in K$ offered to the market, buyers self-select into $n+1$ groups defined by $\vec{t}=\vec{t}(\vec{p}, \vec{\alpha}) \in \Gamma$. Conversely, for every partition $\vec{t} \in \Gamma$ and products $\vec{\alpha} \in[0,1]^{n}$, the contract price $\vec{p}(\vec{t}, \vec{\alpha})$ is given by

$$
p_{i}(\vec{t}, \vec{\alpha})=\sum_{j=i}^{n} \delta_{j} v\left(t_{j}\right),
$$

$\delta_{j}=\alpha_{j}-\alpha_{j+1}>0$ and

$$
\vec{t}=\vec{t}(\vec{p}(\vec{t}, \vec{\alpha}), \vec{\alpha})
$$

This result establishes a one-to-one correspondence between the market for product $\alpha_{i}$, given by $t \in\left[t_{i-1}, t_{i}\right]$, and the price, $p_{i}(\vec{t})$. The next step is to establish a relationship between the quantity offered to the market and the price. Vertical differentiation allows one to uniquely map quantities to market segments for each product, and to their prices. Explicit dependence on $\vec{\alpha}$ is dropped when the context is clear to simplify the expressions. Thus, there is always some implicit set of products, $\vec{\alpha}$. The endogenous choice of $\vec{\alpha}$ is discussed in sections 5 and 6 .

It is assumed that firms supply $\vec{q}=\left\{q_{1}, \ldots, q_{n}\right\}$ to the market, where $q_{i}$ is the supply of product $\alpha_{i}$. All consumers prefer higher coverage to lower, and hence at any market equilibrium $q_{1}$ will sell out first. Since high value customers will always be able to outbid lower value customers, in equilibrium product $\alpha_{1}$ is allocated to types $t \in\left[0, t_{1}\right]$, where:

$$
q_{1}=F\left(t_{1}\right) .
$$

Here $F\left(t_{1}\right)$ is the number of customers of willingness to pay $v\left(t_{1}\right)$ or higher. If $q_{1} \geq 1$ we set $t_{1}=1$. There are now $1-F\left(t_{1}\right)$ consumers in the interval $\left[t_{1}, 1\right]$ competing for product $\alpha_{2}$. This process continues until the market for each product is determined. This process is formally defined by algorithm 1 .

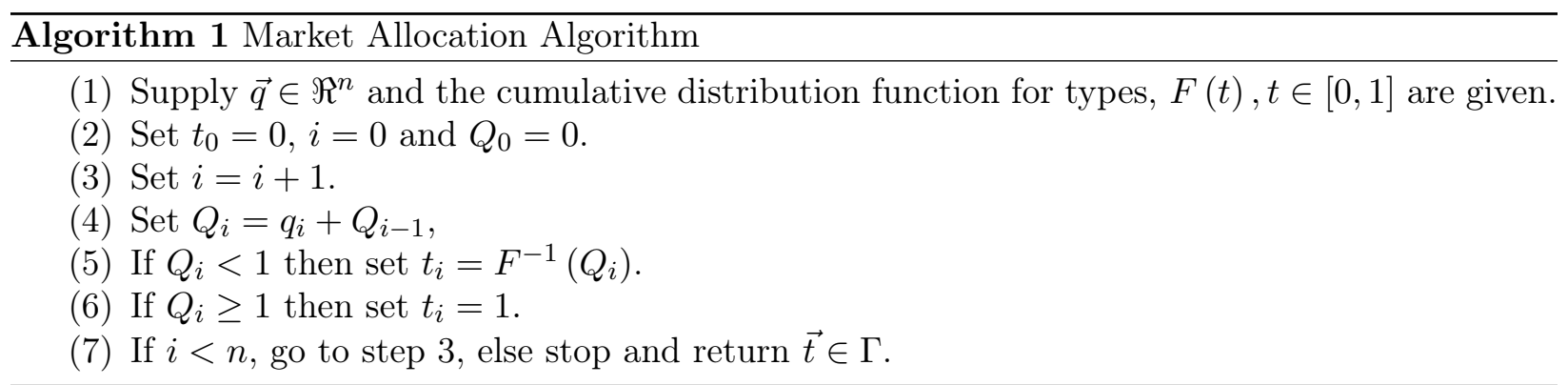

For any quantity $\vec{q} \in \Re_{+}^{n}$ this uniquely defines the market, $\left[t_{i-1}, t_{i}\right]$, for product $\alpha_{i}$. If there is over supply to the market then those firms are notionally allocated to $t_{i}=t_{n+1}=1$ and have no demand for their product. This ensures that $\vec{t}(\vec{q})$ is well defined for any supply of products to the market. Let

$$
T(Q)=F^{-1}(\min (1, Q))
$$


be the type corresponding to total quantity, $Q$, supplied to types $T(Q)$ or less. When $Q \geq 1$ then set $T(Q)=1$. The assumption that $f(t)>0$ for $t \in[0,1]$ ensures that $T(Q)$ is continuous for $Q \geq 0$, and differentiable and strictly increasing for $Q \in[0,1)$.

With this expression one can map total quantity traded to willingness to pay, costs and welfare as follows. Given $Q \in[0,1]$, define:

$$
\begin{aligned}
W(Q) & =\int_{0}^{T(Q)} w(t) f(t) d t=\int_{0}^{Q} w(q) d q \\
C(Q) & =\int_{0}^{T(Q)}(1-t) f(t) d t=\int_{0}^{Q}(1-T(q)) d q \\
V(Q) & =W(Q)+C(Q) .
\end{aligned}
$$

Using the one-to-one relationship between cost types and quantities, given supply $\vec{q}$, prices are uniquely determined by the self-selection constraints:

Proposition 3. Given the distribution of types, $F(t), t \in[0,1]$ and market supply $\vec{q} \in \Re_{+}^{n}$, then under algorithm (1) there is a unique vector of market prices $\vec{p}(\vec{q})=\left\{p_{1}(\vec{q}), \ldots, p_{n}(\vec{q})\right\}$ given by:

$$
p_{i}(\vec{q})=\sum_{j=i}^{n} \delta_{j} v\left(T\left(Q_{j}\right)\right)
$$

where

$$
Q_{j}=\sum_{k=1}^{j} q_{k}
$$

and $\delta_{j}=\alpha_{j}-\alpha_{j+1}\left(\alpha_{n+1} \equiv 0\right)$. Product demand is given by:

$$
d_{i}(\vec{q})=\max \left\{\min \left\{q_{i}, 1-Q_{i-1}\right\}, 0\right\} .
$$

The functions $p_{i}(\vec{q})$ and $d_{i}(\vec{q})$ are continuous in $\vec{q} \in \Re_{+}^{n}$.

Proof. The fact that $f(t)>0$ on $[0,1]$ ensures that for $q \in[0,1], T(q)=F^{-1}(\min (1, q))$ exists, and it is continuous for $q \geq 0$ and strictly increasing for $q \in[0, q)$ since:

$$
\frac{d F^{-1}(q)}{d q}=\frac{1}{f\left(F^{-1}(q)\right)}>0 .
$$

Given $\vec{q}$, this ensures that algorithm (1) is well defined and determines a unique $\vec{t}$. Prices are then defined by (12). The differentiability of $F^{-1}$ ensures that types $t_{i}$ vary continuously with supply, which in turn ensures that prices vary continuously with quantity supplied.

This result ensures that one is able to go from market supply to market clearing prices that satisfy the self-selection constraints for consumers.

4.2. Two Products and a Continuum of Consumers. Ideas from the literature on vertical differentiation (Gabszewicz and Thisse (1979)) and the revelation principal (Myerson (1979)) can be used to specify demand in terms of consumer types. The basic idea can be illustrated with two 
products, $\alpha_{1}>\alpha_{2}$ that are offered at prices $p_{1}>p_{2}$. Types are not observable, and hence consumers self-select into their preferred products. In section 3 it is shown that in this vertically differentiated market, there is a one-to-one mapping between prices and the market shares, defined by $\left\{t_{1}, t_{2}\right\}$. Types $t \in\left[0, t_{1}\right]$ choose product $\alpha_{1}$, while types $t \in\left(t_{1}, t_{2}\right]$ choose product $\alpha_{2}$.

This is illustrated in figure 1. Suppose that the prices for products $\alpha_{1}$ and $\alpha_{2}$ are given by $p_{1}$ and $p_{2}$. The consumer surplus that type $t$ gets from consuming product 2 is defined by:

$$
C S_{2}(t)=\alpha_{2} v(t)-p_{2}
$$

Type $t_{2}$ is defined by the point at which the consumer is indifferent between no insurance and buying product $\alpha_{2}$. This occurs when consumer surplus is zero. For $t>t_{2}$ the consumer surplus from product $\alpha_{2}$ is negative, and hence those consumers prefer no insurance. For consumers $t>t_{2}$ they all prefer $\alpha_{2}$ over no insurance. Product $\alpha_{1}$ has more coverage, but is more expensive. Defining consumer surplus for product $\alpha_{1}$ in a similar fashion, observe that for type $t_{1}$ we have:

$$
C S_{1}\left(t_{1}\right)=\alpha_{1} v\left(t_{2}\right)-p_{1}=C S_{2}\left(t_{1}\right) .
$$

In other words, type $t_{1}$ is indifferent between products $\alpha_{1}$ and $\alpha_{2}$. Since the slope of the willingness to pay for product $\alpha_{1}$ is steeper than for product $\alpha_{2}$ we have single crossing for the consumer surplus curves, and for $t<t_{1}$ consumers strictly prefer coverage $\alpha_{1}$, while the converse is true for $t>t_{1}$.

Thus, product coverage and prices, as well as the self-selection constraints segment the markets by type for each product. Given the distribution of types, this in turn generates a one to one mapping between prices charged and the demand for each product. ${ }^{5}$

Figure 3 also illustrates the average cost curves when the distribution of types is uniform. ${ }^{6}$ The figure is drawn to illustrate the case in which willingness to pay of consumer $t_{1}$ is equal to the average cost of serving customers $t \leq t_{1}$. In the absence of competition from product $\alpha_{2}$ (suppose $\alpha_{2}=0$ ), then firms could charge $p_{1}=\alpha_{1} v\left(t_{1}\right)$, and cover costs with the demand from $t \in\left[0, t_{1}\right]$. But, as the literature on the death spiral has observed (Cutler and Reber (1998)), the introduction of a lower coverage plan, reduces the price that can be charged for the high-coverage plan by an amount equal to the consumer surplus generated by the low-coverage plan, $C S_{2}\left(t_{1}\right)$. In this example price is less than average costs $\left(p_{1}=A C_{1}-C S_{2}\left(t_{1}\right)<A C_{1}\right)$.

\section{Supply}

In the previous section it is shown that prices in this vertically differentiated market are well defined functions of supply and vice versa. Suppose now that market supply is perfectly competitive given the set of products, $\vec{\alpha}$. Firms enter the market if they can earn non-negative profits, and leave if profits are negative. This in turn can be used to define an explicit dynamic process for which there is always a solution. If a stable equilibrium exists, and the market starts near such an equilibrium, then there is convergence to a stable competitive equilibrium.

\footnotetext{
${ }^{5}$ In the case of two goods, demand for products 1 and 2 are respectively given by $q_{1}=F\left(t_{1}\right)$ and $q_{2}=F\left(t_{2}\right)-F\left(t_{1}\right)$, where $F(\cdot)$ is the cumulative distribution function for $f(\cdot)$.

${ }^{6}$ For product 1 the curve is given by $A C_{1}\left(t_{1}\right)=\frac{1}{F\left(t_{1}\right)} \int_{0}^{t_{1}}(1-t) f(t) d t$ and $A C_{2}\left(t_{2}\right)=\frac{1}{F\left(t_{2}\right)-F\left(t_{1}\right)} \int_{t_{1}}^{t_{2}}(1-t) f(t) d t$ for product 2 .
} 


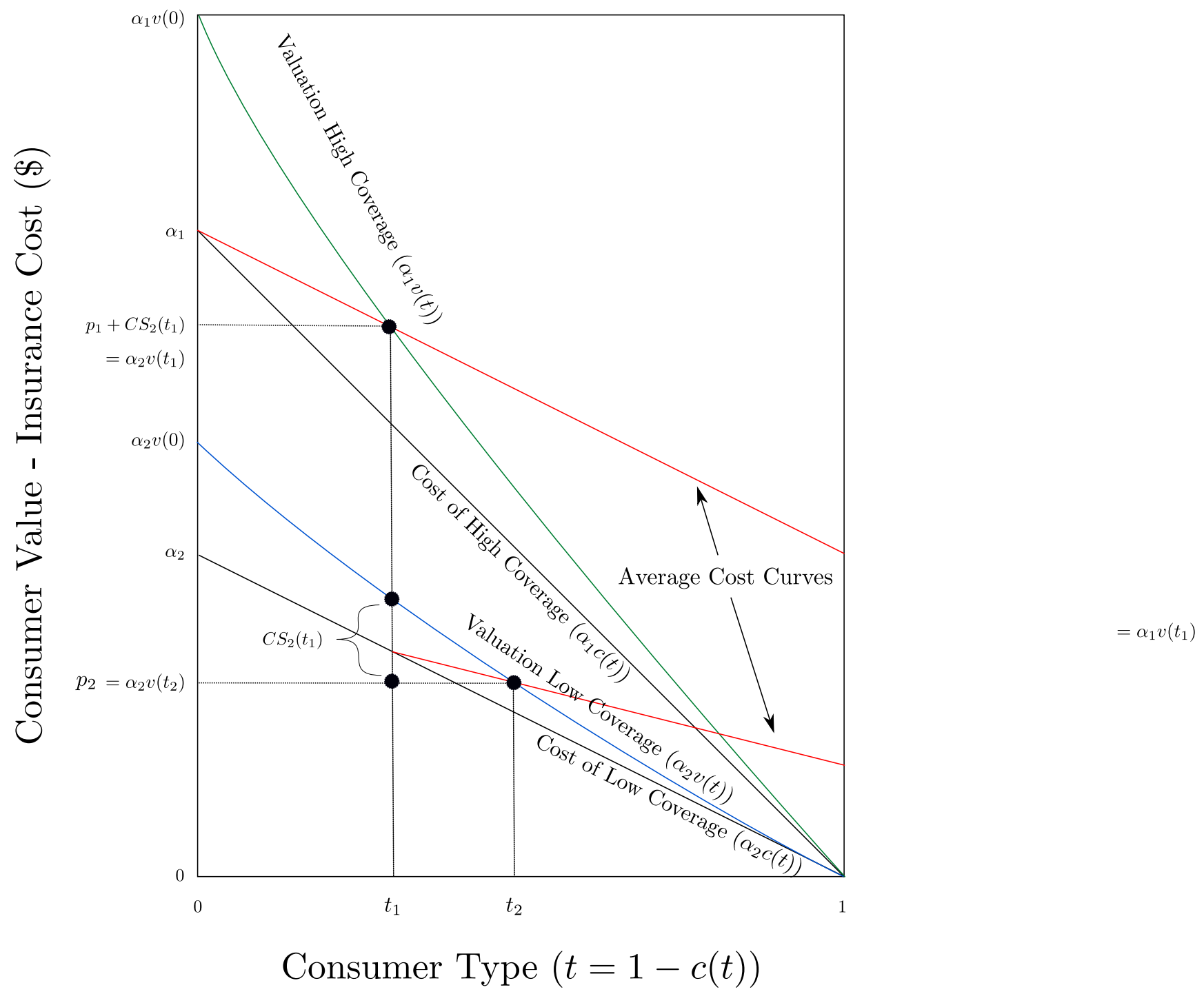

Figure 3. Product Prices and Market Segmentation

It is possible that firm supply is greater than total demand. In that case it is assumed that there is a small cost $k$ of supplying those products to the market. This creates pressure to reduce over supply. For the current case, this simply ensures that there is no excess supply. These costs play a role in dissipating rents in the regulated markets discussed below,

To simplify notation, the quantity vector $\vec{Q}$ is used interchangeably with vector $\vec{q}$. Total supply that is equal to or better than product $\alpha_{i}$ is given by $Q_{i}=\sum_{k=1}^{i} q_{k}$, as defined in (18). From total supply $\vec{Q}$, the supply to market $i$ is given by: $q_{i}=Q_{i}-Q_{i-1}$.

The total cost of supplying $Q_{i}$ is given by $C\left(Q_{i}\right)$ as defined by (15), and hence the cost of supplying $q_{i}$ units of product $\alpha_{i}$ is given by:

$$
C_{i}(\vec{q})=\alpha_{i}\left(C\left(Q_{i}\right)-C\left(Q_{i-1}\right)\right)+k \times\left(q_{i}-d_{i}(\vec{q})\right)
$$


where the last term is the cost of offering to the market a product that is not purchased, where realized demand is given by (19). Given this, the total profits from selling $\alpha_{i}$ is revenue less costs:

$$
\pi_{i}(\vec{q})=d_{i}(\vec{q}) p_{i}(\vec{q})-C_{i}(\vec{q}) .
$$

This definition ensures that profits are well defined for any configuration of product supply. An equilibrium in this market is defined as the limit of explicit supply dynamics. This has a number of benefits relative to a static definition. First, there will always be a solution under weak conditions. In other words suppose that we have an environment for which a static equilibrium does not exist. Presumably if trade occurs in such a market something will happen. By providing a model of dynamics one is able to make predictions even when a static equilibrium does not exist. Moreover, when equilibria do exist, the dynamics can identify stable equilibria, which in turn allows one to make comparative static predictions. Finally, it is shown that the stable equilibria of the model can be found by solving a static optimization problem.

Firm dynamics is modeled as small firms entering or leaving each product category over time depending on the profit signal. Suppose total initial supply is less than 1. Let

$$
\Delta(n)=\left\{\vec{q} \in[0,1]^{n+1} \mid q_{i} \geq 0, \sum_{i=0}^{n} q_{i} \leq 1\right\}
$$

denote the set cases where there is no oversupply $\left(d_{i}(\vec{q})=q_{i}\right)$, and let $\Delta^{0}(n)$ denote the interior of this set. Let $\vec{q}(\tau)$ be the supply at time $\tau$. Suppose that all firms have positive demand,

$$
\vec{q}(0)=\vec{q}^{0} \in \Delta^{0}(n)
$$

The equations of motion are assumed to satisfy:

$$
\frac{d q_{i}(\tau)}{d \tau}=\pi_{i}(\vec{q}(\tau)), i \in\{0,1, \ldots, n\}
$$

Proposition 4. Given $\vec{q}^{0} \in \Delta^{0}(n)$, and $\alpha_{i}>0, i=1, \ldots, n$, there exists a unique solution to (24) with the feature that $q_{i}(\tau)>0$ for all $\tau \geq 0$, and $\lim _{\tau \rightarrow \infty} \sum_{i=1}^{n} q_{i}(\tau) \in \Delta(n)$.

Proof. Observe that for $\vec{q}$ in the interior of $\Delta(n)$ we have that $\pi_{i}(\vec{q})$ is continuously differentiable on $\Delta^{0}(n)$, and continuous on $\Psi=[0, \bar{q}]^{n}$. We can extend this to $[0, \bar{q}]^{n}$, for some constant $\bar{q}>1$ where the directional derivatives of $\pi_{i}$ exist and are bounded, which in turn implies that $\pi_{i}$ is locally Lipschitz continuous on $[0, \bar{q}]^{n}$ (Scholtes $(2012)$ ). This implies that there exists a unique solution to (24) (Hirsch and Smale (1974)). The final step is to observe that for $\vec{q} \in[0, \bar{q}]^{n}$, one has:

$$
\pi_{i}(\vec{q}) \leq q_{i}\left(p_{i}(\vec{q})-k-\alpha_{i} A C_{i}(\vec{q})\right) .
$$

The markup term, $p_{i}(\vec{q})-\alpha_{i} A C_{i}(\vec{q})$, is uniformly bounded below by some $-K$. Hence, if $q_{i}(\tau) \rightarrow 0$, it must be the case $q(\tau) \geq q_{i}(0) e^{-K \tau}>0$ for all $\tau \geq 0$. Finally, if there is excess supply for some firm, profits are necessarily negative, and hence we get the final statement.

Definition 5. Supply $\vec{q}^{*}$ is a competitive equilibrium if $\pi_{i}\left(\vec{q}^{*}\right)=0, i=0, \ldots, n$, and it is a stable equilibrium if, for some open neighborhood $U \subset Q$ of $\vec{q}^{*}$, and for every initial condition $\vec{q}(0) \in \Psi^{0}$, the solution to (24), satisfies $\lim _{\tau \rightarrow \infty} \vec{q}(\tau)=\vec{q}^{*}$. 
The stability of a solution can be studied using a Liapunov function. A natural function in our case is:

$$
L(\vec{q})=\sum_{i=1}^{n} \pi_{i}^{2}(\vec{q}) \geq 0 .
$$

Notice that finding competitive equilibria is equivalent to solving $\min _{\vec{q} \in \Psi^{0}, L}(\vec{q})$. The stability of such equilibria can be determined using the properties of the Liapunov function.

Proposition 6. Suppose that all firms have positive demand at an equilibrium: $\vec{q}^{*} \in \Delta^{0}(n)$. If $\vec{q}^{*}$ is an isolated equilibrium then it is a stable equilibrium if the matrix of gradients of the profit functions, $H\left(\vec{q}^{*}\right)=\left\{\nabla \pi_{i}(\vec{q})\right\}_{i \in\{1 \ldots, n\}}$, is strictly negative definite.

Proof. At an equilibrium, profits are zero and hence $L\left(\vec{q}^{*}\right)=0$. To show that this equilibrium is stable, a sufficient condition is that $\frac{d L(\vec{q}(\tau))}{d \tau}<0$ for any $\vec{q}(0)$ in an open neighborhood of $\vec{q}^{*}$. Using (24) observe:

$$
\begin{aligned}
\frac{d L(\vec{q}(\tau))}{d \tau} & =\sum_{i=0}^{n} 2 \pi_{i}(\vec{q}(\tau)) \sum_{j=0}^{i} \frac{\partial \pi_{i}(\vec{q}(\tau))}{\partial q_{j}} \frac{d q_{j}(\tau)}{d \tau} \\
& =2 \vec{\pi}(\vec{q}(\tau))^{T} H(\vec{q}(\tau)) \vec{\pi}(\vec{q}(\tau))
\end{aligned}
$$

where $\vec{\pi}(\vec{q})^{T}=\left[\pi_{0}(\vec{q}), \ldots, \pi_{n}(\vec{q})\right]$. Since $\vec{q}^{*} \in \Psi^{0}$, then one can choose the neighborhood of $\vec{q}^{*}$ to be a subset of $\Psi^{0}$. Moreover on this subset $H(\vec{q})$ is continuous, so the subset can be made sufficiently small so that $H(\vec{q})$ is strictly negative semi-definite on this subset. Since the equilibrium is isolated this implies that $\frac{d L(\vec{q}(\tau))}{d \tau}<0$, and by the Liapunov theorem this implies that $\vec{q}^{*}$ is stable (Hirsch and Smale (1974)).

Thus, finding stable equilibria for this market can be achieved by solving the static optimization problem $\min _{\vec{q} \in \Psi} L(\vec{q})$, and then checking to see whether $H\left(\vec{q}^{*}\right)$ is negative definite (which can be done quickly by computing the real eigenvalues of the matrix). Even if an equilibrium does not exist, the model makes predictions regarding the evolution of supply in the market.

The case of a single product, with a uniform distribution of customers, is illustrated in figure 4. The quantities to the left of the equilibrium have prices greater than average costs, and hence supply increases. Conversely, to the right of the equilibrium, average costs are greater than price, resulting in a decreases in supply.

It is well known that markets with adverse selection can exhibit multiple equilibria. This occurs when the price curve is flatter than the average cost curve. This is illustrated in figure 5 where there are three equilibria. This figure has exactly the same parameters as the previous figure, the only difference is with the distribution of types. There is a mass of individuals around $t=0.3$. In quantity space this results in a flattening of the price curve. Since costs are averaged over the interval from zero until $t$, the slope is less sensitive to a mass of consumers, resulting in a double crossing of the average cost curve by the price curve. The equilibrium in the center is unstable because if quantity is slightly lower, then price is less than average costs. Thus firms reduce output until the equilibrium on the far left is reach. The converse occurs to the right. 

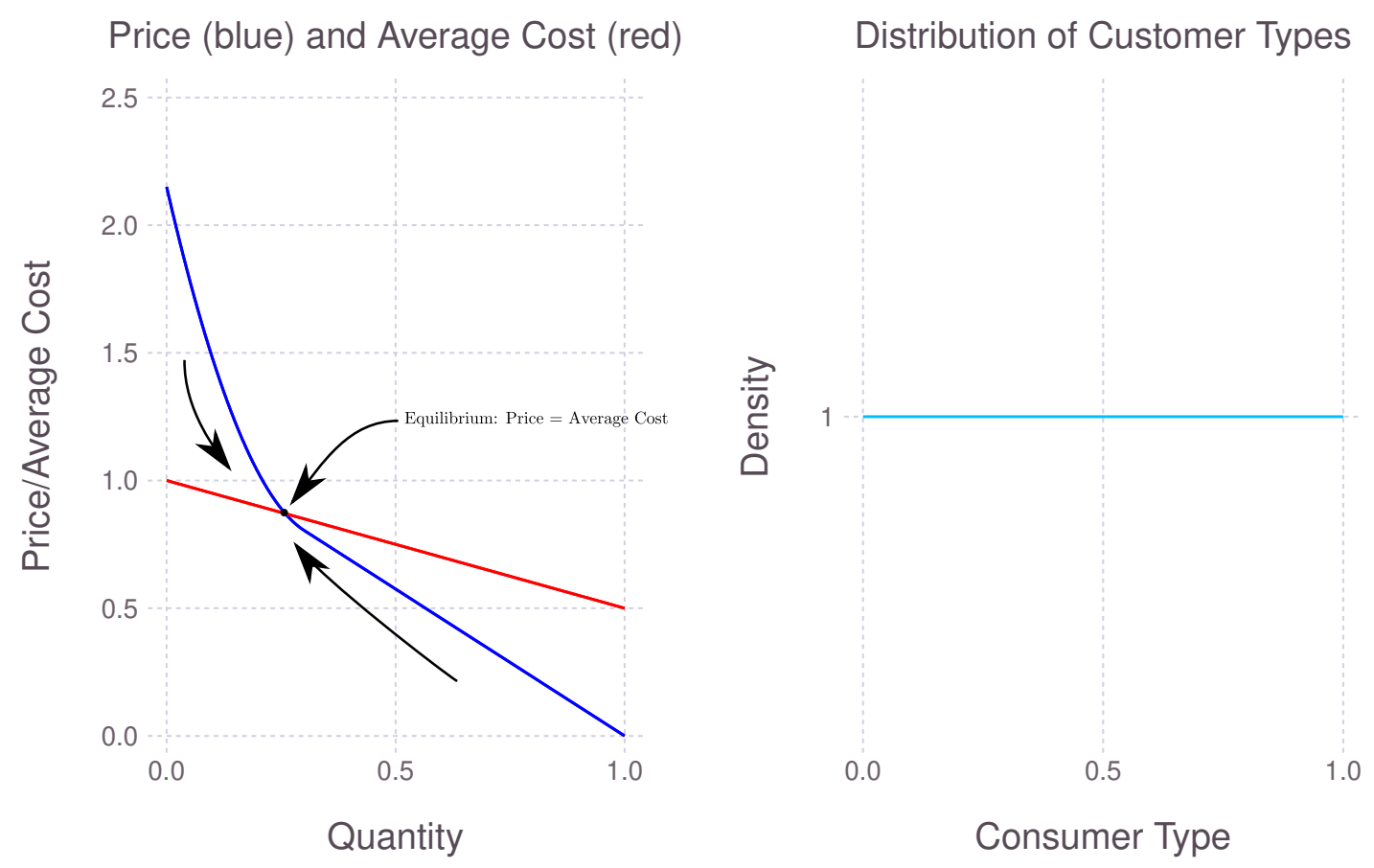

Figure 4. Equilibrium with Uniform Distribution of Customer Types

Price (blue) and Average Cost (red)
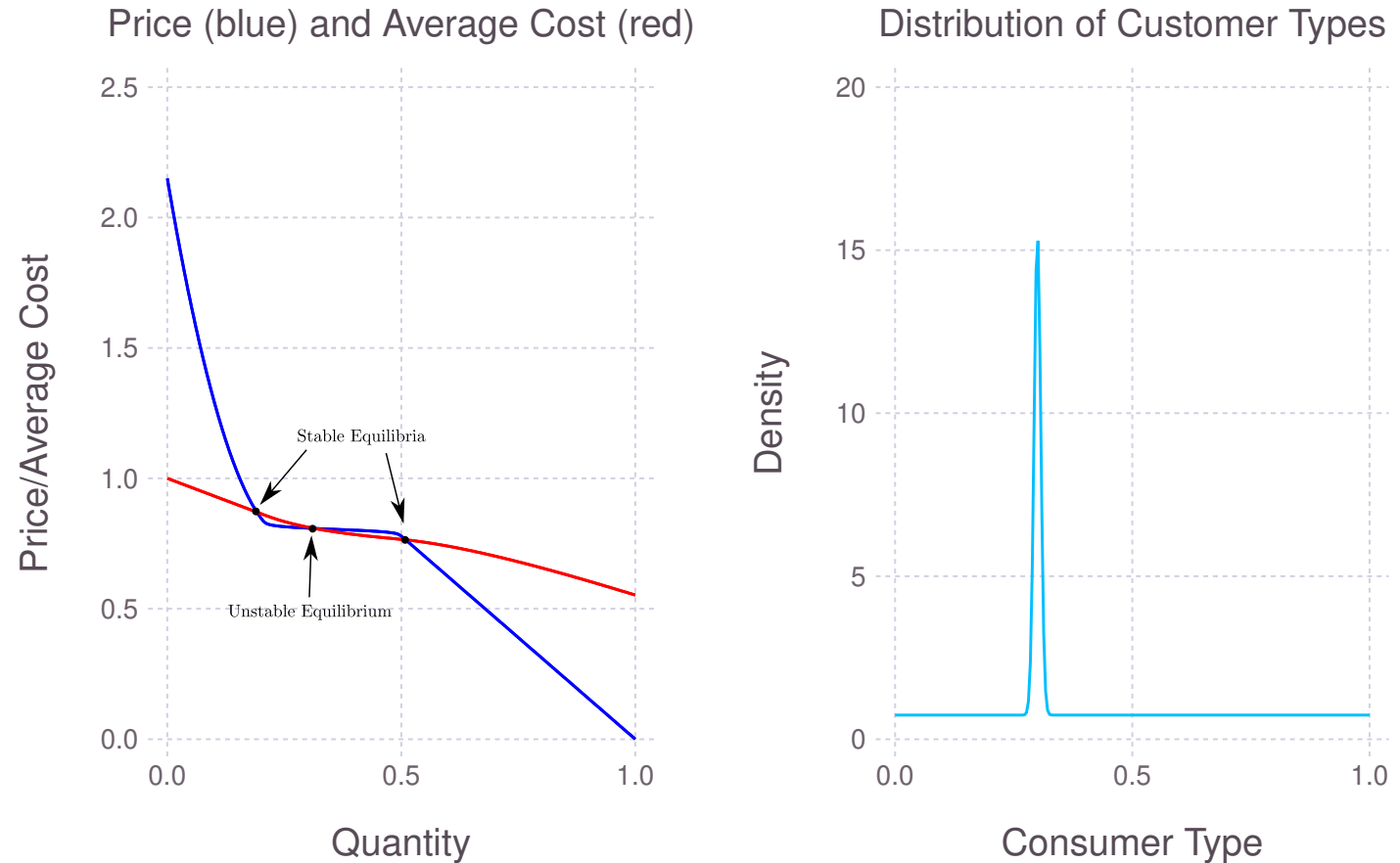

Figure 5. Multiple Competitive Equilibria

\section{The One and Two Margin Problems}

An implication of adverse selection at a competitive equilibrium with a single product is that many low value consumers prefer not to purchase insurance. One policy response to this is the introduction 
of an insurance mandate, the requirement that individuals who do not purchase insurance pay a price/tax $p^{M}{ }^{7}$ A number of authors, including Handel et al. (2015), Hackmann et al. (2015), and Einav et al. (2010), have provided estimates on the welfare effects of the mandate on the intensive and extensive margin. Geruso et al. (2019) extends that analysis to measure the welfare effects taking account of the effect of the mandate on both margins. Azevedo and Gottlieb (2017) show that the insurance mandate has the largest effect on the extensive margin, but an increase in the mandate price also reduces demand for high-coverage plans. The purpose of this section is to show that one gets the same result in this model, and shows how the direction and size of the effect depends on the stability of the market equilibrium and the distribution of costs.

Consider first the case of single product with coverage $\alpha_{1}$. Suppose that there is a unique, stable equilibrium in this market. Let $p^{M}$ be the mandate price. Then the market equilibrium is completely characterized by the marginal consumer $t_{1}\left(p^{M}\right)$ as follows. Consumers with $t \in\left[0, t_{1}\left(p^{M}\right)\right)$ buy product $\alpha_{1}$, while consumers in $\left(t_{1}\left(p^{M}\right), 1\right]$ do not buy insurance and pay the mandate $p^{M}$. The marginal consumer, $t_{1}\left(p^{M}\right)$, is indifferent between purchasing $\alpha_{1}$ and no insurance:

$$
\alpha_{1} v\left(t_{1}\left(p^{M}\right)\right)-p_{1}\left(p^{M}\right)=-p^{M},
$$

and hence the price is given by:

$$
p_{1}\left(p^{M}\right)=\alpha_{1} v\left(t_{1}\left(p^{M}\right)\right)+p^{M} .
$$

At a competitive equilibrium the price is equal to average cost. We define the price markup over average costs by:

$$
m_{1}\left(t_{1}\right)=\alpha_{1}\left(v\left(t_{1}\left(p^{M}\right)\right)-A C_{1}\left(t_{1}\right)\right),
$$

where the average costs function is given by:

$$
A C_{1}\left(t_{1}\right)=\frac{1}{F\left(t_{1}\right)} \int_{0}^{t_{1}}(1-t) f(t) d t
$$

The price markup describes the markup when there is no mandate $\left(p^{M}=1\right)$. Profits are given by $q_{1} m_{1}$, and hence it follows that $t_{1}\left(p^{M}\right)$ is a stable equilibrium if and only if:

$$
\begin{aligned}
m_{1}\left(t_{1}\left(p^{M}\right)\right) & =-p^{M}, \\
\frac{d m_{1}\left(t_{1}\left(p^{M}\right)\right)}{d t_{1}} & <0 .
\end{aligned}
$$

From this, one gets:

$$
\frac{d t_{1}}{d p^{M}}=\frac{-1}{\frac{d m_{1}\left(t_{1}\left(p^{M}\right)\right)}{d t_{1}}}>0 .
$$

In other words, in the one product case, an increase in the mandate price leads to greater insurance coverage. The welfare effect can be computed as follows. Welfare is given by:

$$
W\left(t_{1}\right)=\alpha_{1} \int_{0}^{t_{1}} w(t) f(t) d t .
$$

\footnotetext{
${ }^{7}$ In the context of this model, this is equivalent to setting $p_{n+1}=p^{M}$. All the analysis on the equivalence between prices and quantities apply to this case.
} 
Thus the welfare consequence of an increase in the mandate is:

$$
\begin{aligned}
\frac{d W\left(t_{1}\left(p^{M}\right)\right)}{d p^{M}} & =\alpha_{1} w\left(t_{1}\left(p^{M}\right)\right) f\left(t_{1}\left(p^{M}\right)\right) \frac{d t_{1}}{d p^{M}}, \\
& =\alpha_{1} w\left(t_{1}\left(p^{M}\right)\right) \frac{d q_{1}}{d p^{M}}>0 .
\end{aligned}
$$

Thus, an increase in the mandate increases both participation and welfare. The second line follows immediately from the fact that $q_{1}=F\left(t_{1}\right)$. Hence, the amount of welfare increase is proportional to the coverage of the product, $\alpha_{1}$, the welfare of the marginal consumers, $w\left(t_{1}\right)$, and the number of additional consumers, $\frac{d q_{1}}{d p^{M}}$.

Consider now the two product case, as in Geruso et al. (2019), where the products are $1 \geq \alpha_{1}>$ $\alpha_{2}>0$. Assume that there exists a stable competitive equilibrium with two products:

$$
0<t_{1}\left(p^{M}\right)<t_{2}\left(p^{M}\right)
$$

- The price for product 2 has to be set so consumer of type $t_{2}\left(p^{M}\right)$ is indifferent between no insurance and buying product $\alpha_{2}$ :

$$
\alpha_{2} v\left(t_{2}\left(p^{M}\right)\right)-p_{2}=-p^{M}
$$

and thus:

$$
p_{2}=\alpha_{2} v\left(t_{2}\left(p^{M}\right)\right)+p^{M} .
$$

Similarly, the price for product $\alpha_{1}$ has to be set to make the consumer of type $t_{1}\left(p^{M}\right)$ indifferent between buying product $\alpha_{1}$ and product $\alpha_{2}$ :

$$
\alpha_{1} v\left(t_{1}\left(p^{M}\right)\right)-p_{1}=\alpha_{2} v\left(t_{1}\left(p^{M}\right)\right)-p_{2} .
$$

Using the formula for price $p_{2}$, and consistent with proposition 2, one has:

$$
p_{1}=\delta_{1} v\left(t_{1}\left(p^{M}\right)\right)+\alpha_{2} v\left(t_{2}\left(p^{M}\right)\right)+p^{M},
$$

where $\delta_{1}=\alpha_{1}-\alpha_{2}>0$.

It is interesting to observe that an increase in the mandate price results in 1-1 increase in all prices in the market. This allows one to characterize the equilibrium using the mark up definitions for a market without a mandate and set these equal to the mandate cost to the consumer:

$$
\begin{aligned}
& m_{1}\left(t_{1}\left(p^{M}\right), t_{2}\left(p^{M}\right)\right)=-p_{m}, \\
& m_{2}\left(t_{1}\left(p^{M}\right), t_{2}\left(p^{M}\right)\right)=-p_{m} .
\end{aligned}
$$

where the formulas for the mark up are given by:

$$
\begin{aligned}
& m_{1}\left(t_{1}\left(p^{M}\right), t_{2}\left(p^{M}\right)\right)=\delta_{1} v\left(t_{1}\left(p^{M}\right)\right)+\alpha_{2} v\left(t_{2}\left(p^{M}\right)\right)-\alpha_{1} A C_{1}\left(t_{1}\right), \\
& m_{2}\left(t_{1}\left(p^{M}\right), t_{2}\left(p^{M}\right)\right)=\alpha_{2}\left(v\left(t_{2}\left(p^{M}\right)\right)-A C_{2}\left(t_{1}, t_{2}\right)\right),
\end{aligned}
$$


and the average cost functions are:

$$
\begin{aligned}
& A C_{1}\left(t_{1}\right)=\frac{1}{F\left(t_{1}\right)} \int_{0}^{t_{1}}(1-t) f(t) d t \\
& A C_{2}\left(t_{2}\right)=\frac{1}{F\left(t_{2}\right)-F\left(t_{1}\right)} \int_{t_{1}}^{t_{2}}(1-t) f(t) d t .
\end{aligned}
$$

Given these preliminaries one has the following result:

Proposition 7. Suppose that with two products $\left\{\alpha_{1}, \alpha_{2}\right\}$ and mandate price $p^{M}$ there is a stable competitive equilibrium with positive demand for both products, given by $\left\{0<t_{1}\left(p^{M}\right)<t_{2}\left(p^{M}\right)<1\right\}$. Then increasing the mandate price results in fewer individuals purchasing the high-coverage product $\left(d q_{1} / d p^{M}<0\right)$, and an increase in the total number of individuals purchasing insurance $\left(d Q / d p^{M}>\right.$ $0)$, where $Q=q_{1}+q_{2}$ is total demand for insurance.

See the appendix for the proof and detailed computation of the comparative static results. This result provides a formal foundation for the graphical analysis in Geruso et al. (2019). The key observation is that the stability of the competitive equilibrium allows one to sign the effects of increasing the mandate. This result can be used to derive a formula for the welfare consequences of increasing the mandate in this case:

Corollary 8. The welfare effect of increasing the mandate price is

$$
\frac{d W}{d p^{M}}=\alpha_{2} w\left(t_{2}\left(p^{M}\right)\right) \frac{d Q}{d p^{M}}+\delta_{1} w\left(t_{1}\left(p^{M}\right)\right) \frac{d q_{1}}{d p^{M}} .
$$

The proof is in the appendix. Observe that one cannot sign the welfare effect of a mandate increase. There are two terms. The first is the positive coverage effect, $\alpha_{2} w\left(t_{2}\left(p^{M}\right)\right) \frac{d Q}{d p^{M}}>0$. It is proportional to the coverage of product $\alpha_{2}$, the welfare gain of the marginal consumer, $w\left(t_{2}\right)$, and the size of the response, $\frac{d Q}{d p^{M}}$. This effect is partially offset by the negative effect on welfare of the reduction in consumers purchasing the high-coverage good, given by $\delta_{1} w\left(t_{1}\left(p^{M}\right)\right) \frac{d q_{1}}{d p^{M}}<0$. The size of this effect depends on the difference in coverage between the two products, $\delta_{1}=\alpha_{1}-\alpha_{2}$, and the welfare of the consumer who is indifferent between products $\alpha_{1}$ and $\alpha_{2}$.

This formal analysis is consistent with the graphical analysis of Geruso et al. (2019), and shows that in addition to the assumption of vertical differentiation of product coverage, one also needs to suppose that the equilibrium is stable to sign the effect at both the intensive and extensive margins. They show empirically that it is possible for the negative effects of substituting from a high-coverage to a low-coverage plan to offset the benefits of increased coverage for the whole population. A limitation of the graphical approach is that it is not easily extended to more products. For the remainder of the paper we consider markets where free entry of products is a policy option, and then ask which type of market structure is optimal.

\section{The Death Spiral}

This section derives the equilibrium when there is free entry of insurance plans, and provides a complete characterization of the "death spiral" (Cutler and Zeckhauser (1998) and Cutler and Reber (1998)). The equilibrium is a "death spiral" in the sense that the market share of the efficient 
contract is driven to zero. However, at a competitive equilibrium, all consumers get some insurance coverage. Using this characterization it is possible to derive the effect of a minimum coverage standard and an insurance mandate on the free entry equilibrium.

Observing that if plans $\alpha_{i}>\alpha_{i+1}$ are in the market at some competitive equilibrium, then, from the discussion above regarding the single crossing problem, it is always possible for a plan $\alpha \in\left(\alpha_{i}, \alpha_{i+1}\right)$ to enter the market and get positive demand at positive profits. Hence, if an equilibrium exists it must consist of a continuum of plans, with possibly some lower and upper bounds where there is pooling of types.

The revelation principle can be used to derive the exact form of prices, and product coverage, given the self selection-constraints. Consider a consumer of type $t$ who is assigned plan $\alpha(t)$ at price $p(t)$. At a continuum equilibrium each type gets a plan tailored to her characteristics, and hence average price is equal to marginal costs, and the competitive price must satisfy:

$$
p(t)=\alpha(t)(1-t) .
$$

The revelation principle implies that a consumer of type $t$ should not prefer to purchase a product designed for some other type $\hat{t}$. The payoff when consumer $t$ chooses the plan for type $\hat{t}$ is:

$$
u(\hat{t} \mid t)=\alpha(\hat{t}) v(t)-p(\hat{t})
$$

where $\alpha(\hat{t}) v(t)$ is the value consumer $t$ gets from purchasing product $\hat{t}$, while $p(\hat{t})$ is the price she pays for this product. A necessary condition for type $t$ to truthfully reveal her type is:

$$
\left.\frac{\partial u(\hat{t} \mid t)}{\partial \hat{t}}\right|_{\hat{t}=t}=0 .
$$

Using (25) and (26), the differential equation 27 implies at $\hat{t}=t$ :

$$
\alpha^{\prime}(t)=-\frac{\alpha(t)}{w(t)} .
$$

This equation can be rewritten in the form:

$$
\frac{d \log (\alpha(t))}{d t}=\frac{-1}{w(t)} .
$$

The argument above that shows that the solution must be a continuum also implies that type $t=0$ is served. In that type there is no adverse selection, thus type $t=0$ is served by the high-coverage product, and hence $\alpha(0)=1$. Adverse selection implies that one cannot have the high-coverage product service some types $t \in[0, \epsilon]$ and satisfy the zero profit condition. Some type $\alpha<1$ can always profitably enter and take some of the market. ${ }^{8}$ This fixes the starting point for the differential equation 29, from which we can derive the following result (the full proof is in the appendix).

Proposition 9. Suppose that welfare falls with type, $w^{\prime}(t)<0$ for $t \in[0,1)$, then the stable free entry equilibrium is characterized by consumer $t$ buying product $\alpha^{0}(t)$ at price $p^{*}(t)=\alpha^{*}(t)(1-t)$

\footnotetext{
${ }^{8}$ Notice that when $\epsilon>0$, the competitive price of product with coverage $\alpha=1$ is $p=A C=\int_{0}^{\epsilon}(1-t) f(t) d t<1$. Thus, there is a $\tilde{t} \in(0, \epsilon)$ such that $1-\tilde{t}<p$ and $v(\tilde{t})-(1-\tilde{t})>v(\tilde{t})-p$. Thus there exists an $\tilde{\alpha}$ such that $\tilde{\alpha}(v(\tilde{t})-(1-\tilde{t}))=v(\tilde{t})-p$, which in turn implies that types $t \in[\tilde{t}, \epsilon]$ will buy $\tilde{\alpha}$ and earn a profit for the entrant.
} Hence $\epsilon>0$ cannot be an equilibrium. 
where

$$
\alpha^{0}(t)=\exp \left(-\int_{0}^{t} \frac{1}{w(\tau)} d \tau\right)
$$

This result has a number of features worth noting. In addition to only type $t=0$ receiving the high-coverage product, there is a complete unraveling of the market in the sense that all product types are sold in equilibrium since $\lim _{t \rightarrow 1} \alpha(t)=0$, and the speed at which coverage falls is given by (28). Also, prices are completely determined by the self-selection constraints with respect to consumer costs. This fact is not obvious when one studies the finite case because average costs depend on the distribution of consumer types, and hence the equilibrium price will always depend on the type distribution. Under free entry of products, prices converge to marginal costs and coverage is completely determined by the welfare function, $w(t)$, and total consumer welfare is given by:

$$
W^{0}=\int_{0}^{1} \alpha^{0}(t) w(t) f(t) d t \in\left(0, W^{*}\right),
$$

where $W^{*}=\int_{0}^{1} w(t) f(t) d t$ is the maximum perfect information consumer welfare.

A Linear Example. Consider the linear case in which $w(t)=\beta(1-t)$ and hence $v(t)=$ $(1+\beta)(1-t), \beta>0$, and the distribution of types is uniform $(f(t)=1)$. Substituting this into (30) implies:

$$
\begin{aligned}
\alpha^{0}(t) & =\exp \left(-\int_{0}^{t} \frac{1}{\beta(1-\tau)} d \tau\right) \\
& =\exp \left(\left[\frac{1}{\beta} \log (1-\tau)\right]_{0}^{t}\right) \\
& =\exp \left(\left[\log (1-\tau)^{1 / \beta}\right]_{0}^{t}\right) \\
& =(1-t)^{1 / \beta}
\end{aligned}
$$

From this we get the price function:

$$
p^{0}(t)=(1-t)^{(1+\beta) / \beta} .
$$

At this equilibrium, all types are served, and the speed of coverage decline depends upon $\beta$. For this example we can compare the welfare under the first best with free entry equilibrium with a uniform distribution. At the first best we have:

$$
\begin{aligned}
W^{*} & =\beta \int_{0}^{1}(1-t) d t \\
& =\beta / 2 .
\end{aligned}
$$


While at the competitive equilibrium we have that total welfare is less than the first best:

$$
\begin{aligned}
W^{0} & =\beta \int_{0}^{1} \alpha^{*}(t)(1-t) d t \\
& =\beta \int_{0}^{1}(1-t)^{(1+\beta) / \beta} d t \\
& =\frac{\beta^{2}}{1+2 \beta}<W^{*} .
\end{aligned}
$$

In this example the parameter $\beta$ provides a measure of the gain from insurance. We can work out the relative efficiency of the free entry equilibrium with the first best:

$$
R E(\beta)=\frac{W^{0}}{W^{*}}=\frac{2 \beta}{1+2 \beta} .
$$

When there are no gains from trade $(\beta=0)$ the relative efficiency is zero $(R E(0)=0)$. One has $\lim _{\beta \rightarrow \infty} R E(\beta)=1$ and hence for steeply declining welfare, the free entry equilibrium is close to efficient.

\section{The Effect of a Minimum Coverage Standard and an Insurance Mandate}

A feature of the "death spiral" is that lower valuation consumers purchase lower coverage products. Frean et al. (2017) emphasize that a goal of public policy is to improve the coverage of insurance that low valuation individuals consume. This section considers the effect of two policies that have been used to address this issue: the insurance mandate and coverage standards. Insurance mandates are implemented by requiring consumers to pay a price/tax/fine $p^{M}>0$ if they do not buy insurance. Under the free entry equilibrium, all consumers buy some insurance, hence, in the absence of a minimum coverage standard, a mandate has no effect! Thus, one needs to consider insurance mandates in conjunction with minimum coverage standards.

With both a mandate and minimum coverage standard, the competitive free entry equilibrium has a simple structure that can be conveniently described in consumer type space. One can then find the optimal coverage standard and mandate. At a competitive free entry equilibrium, type $t$ is consuming coverage $\alpha(t)$ that is decreasing with type until type 0 gets a zero coverage product. A minimum coverage standard $\bar{\alpha} \in(0,1)$ is equivalent to requiring that types $t \geq \bar{t}$ get coverage $\alpha(\bar{t})=\bar{\alpha}$. But now consumers of type $t \geq \bar{t}$ have the choice between no insurance (and pay the mandate) or purchase coverage $\bar{\alpha}$.

This choice leads to demand for the low-coverage product that is fixed by the insurance mandate. Rather than set the mandate price, suppose that the planner chooses the lowest type to have coverage at level $\bar{\alpha}$, given by type $t^{M} \in[\bar{t}, 1]$.

With free entry of products, these policies have no effect on the market prices for products $\alpha>\bar{\alpha}$ since these are being provided at cost. In the free entry model firms do not set prices, but respond to prices/demand. Thus, the self-selection constraint for the high-coverage goods fixes the price of the lowest coverage product at:

$$
\bar{p}(\bar{t})=\underset{24}{\alpha(\bar{t})}(1-\bar{t}) .
$$


Type $t^{M}$ will be indifferent between buying product $\bar{\alpha}$ at price $\bar{p}(\bar{t})$ and no insurance at the mandated price $p^{M}$ if and only if:

$$
u\left(\bar{p}, \bar{\alpha} \mid t^{M}\right)=\bar{\alpha} v\left(t^{M}\right)-\bar{p}(\bar{t})=-p^{M},
$$

where $\bar{p}$ is the competitive price of the minimum coverage good. Thus the mandate price is given by:

$$
\begin{aligned}
p^{M}\left(\bar{t}, t^{M}\right) & =\bar{p}(\bar{t})-\bar{\alpha} v\left(t^{M}\right) \\
& =\alpha(\bar{t})\left(1-\bar{t}-v\left(t^{M}\right)\right) .
\end{aligned}
$$

However, due to falling average costs, the price $\bar{p}=\bar{\alpha}(1-\bar{t})$, is greater than the cost of serving customers $t \in\left[\bar{t}, t^{M}\right]$.

The minimum coverage constraint implies that firms offering the lowest coverage at the free entry equilibrium price will be earning a rent. Klein and Leffler (1981) observe that in competitive market where there are rents, then firms find ways to dissipate these rent. In this model we allow firms to have supply that exceeds demand, that in turn imposes a cost on them that serves to dissipate rents. The profit from the sale to the low-coverage market in terms of the policy choices $\left\{\bar{t}, t^{M}\right\}$ is given by:

$$
\begin{aligned}
\pi\left(\bar{t}, t^{M}\right) & \equiv \alpha(\overline{\mathrm{t}})\left(\int_{\bar{t}}^{t^{M}}\{(1-\bar{t})-(1-t)\} f(t) d t\right) \\
& =\alpha(\overline{\mathrm{t}})\left(\int_{\bar{t}}^{t^{M}}(t-\bar{t}) f(t) d t\right) \geq 0 .
\end{aligned}
$$

These profits will be dissipated with an oversupply of products to the market. Let $Q^{E S}$ be the excess supply, then we have:

$$
\pi\left(\bar{t}, t^{M}\right)=k \times Q^{E S} .
$$

In practice firms might find other ways to dissipate this rent, such as offering health club memberships, or other costly, non-pecuniary products unrelated to health insurance. From the point of view of welfare, we can view these rents as pure social waste that we need to incorporate into the welfare calculation. The following proposition summarizes this discussion:

Proposition 10. A minimum coverage standard $\bar{\alpha} \in(0,1)$ and mandate price $p^{M} \in[0, \bar{p}]$, where $\bar{p}$ is the competitive price, given by (31) for product $\bar{\alpha}$, results in consumers $t \in[0, \bar{t}]$ purchasing product $\alpha(t)$, the free market coverage for their types. Types $t \in\left[\bar{t}, t^{M}\right]$ purchase the lowest coverage product, $\bar{\alpha}$, at price $\bar{p}$. The remaining consumers purchase no insurance. Conversely, given type $\bar{t} \in(0,1)$ and $t^{M} \in\left[0, t^{0}(\bar{t})\right)$, where $v\left(t^{0}\right)=1-\bar{t}$, one can set the minimum coverage standard, $\bar{\alpha}=\alpha(\bar{t})$, and insurance mandate $p^{M}$ to satisfy (33), to divide consumers into the three groups receiving insurance from a competitive market, at the minimum coverage standard and no insurance respectively.

This proposition shows that there is a one-to-one correspondence, via the self-selection constraints, between the policy instruments and dividing consumers into three groups, those buying at the free market (death spiral) prices, the minimum coverage standard and no-insurance. The next step is 
to compute the welfare consequences of this intervention, and computing the optimal minimum standard and mandate price. One of the reasons policy makers prefer private provision of services is due to the dead-weight loss associated with raising public funds and then transferring them to private entities. Hence, it is also assumed that public transfers impose a cost, as is assumed in the regulation literature (see Laffont and Tirole (1986) and Caillaud et al. (1988)). Let $\lambda \geq 0$ be the marginal cost of public funds. This will be used to adjust the cost of the mandate. Notice that this allows us to explore the effect of different beliefs regarding the mandate.

Given a policy $\left\{\bar{t}, t^{M}\right\}$ the welfare consequences are given by the welfare from each group in the market. For individuals who get insurance products at the death spiral prices equilibrium welfare is:

$$
W^{0}\left(\bar{t}, t^{M}\right)=\int_{0}^{\bar{t}} \alpha(t) w(t) f(t) d t .
$$

Consumers are getting insurance at competitive prices, however due to adverse selection the coverage is falling with type. For the consumers getting the low-coverage product we have:

$$
W^{1}\left(\bar{t}, t^{M}\right)=\int_{\bar{t}}^{t^{M}} \alpha(\bar{t}) w(t) f(t) d t-\pi\left(\bar{t}, t^{M}\right) .
$$

In this case the profits are being wastefully dissipated via overproduction, and hence they have to be subtracted from the welfare gain of supplying this market segment. Finally, the lowest types are paying the mandate, which is a cost due to the use of the government to redistributed the income. The mandate may have a positive or negative price. In either case there is a cost of carrying out the transfer. The total transfer is:

$$
\begin{aligned}
G\left(\bar{t}, t^{M}\right) & =\left|\left(1-F\left(t^{M}\right)\right) p^{M}\right| \\
& =\left(1-F\left(t^{M}\right)\right) \alpha(\bar{t}) \times\left|1-\bar{t}-v\left(t^{M}\right)\right|,
\end{aligned}
$$

where $p^{M}$ is the mandate price given by (32). Hence, total welfare is given by:

$$
W\left(\bar{t}, t^{M}\right)=W^{0}\left(\bar{t}, t^{M}\right)+W^{1}\left(\bar{t}, t^{M}\right)-\lambda G\left(\bar{t}, t^{M}\right) .
$$

Consider first the case in which there is no social cost of transfer, $\lambda=0$ and $\bar{t}<t^{M}<1$. Using the derivative of coverage with type, (28). we have:

$$
\begin{aligned}
\frac{\partial W}{\partial \bar{t}} & =-\frac{\partial \pi\left(\bar{t}, t^{M}\right)}{\partial \bar{t}}, \\
& =w(\bar{t}) \pi\left(\bar{t}, t^{M}\right) \\
& >0 .
\end{aligned}
$$

Similarly, we have for $t^{M}$ :

$$
\begin{aligned}
\frac{\partial W}{\partial t^{M}} & =-\frac{\partial \pi\left(\bar{t}, t^{M}\right)}{\partial t^{M}} \\
& =-\left(t^{M}-\bar{t}\right) f\left(t^{M}\right)<0
\end{aligned}
$$


Together, this implies at the optimum $\bar{t}=t^{M}$, no bunching at the minimum coverage. Thus welfare can be written as

$$
W(\bar{t})=\int_{0}^{\bar{t}} \alpha(t) w(t) f(t) d t
$$

In this case $\frac{d W(\bar{t})}{d t}>0$, and hence it is optimal to set $\bar{t}=1$. Observe that at this solution there are no transfers. Since transfers increase the costs when we have a mandate or minimum coverage standard then we can conclude:

Proposition 11. In a competitive insurance market with free entry, if the only policy instruments are a minimum coverage standard and an insurance mandate then regardless of the social cost of public transfers, it is optimal to have no minimum standard and no mandate.

The result is quite intuitive. When a minimum coverage standard is imposed one is reducing choice relative to a free entry equilibrium. The marginal type is buying her preferred product $\bar{\alpha}=\alpha(\bar{t})$ at cost. All lower valuation types, $t \geq \bar{t}$ were free to purchase this product before regulation, but chose a lower coverage product. In essence regulation is reducing choice, and creating inefficient rents via an excessive supply of the lowest coverage good.

\section{Optimal Insurance}

In this section we continue to assume the existence of adverse selection, but consider a policy that entails more intervention. Specifically suppose that the government can control the number and coverage of products provided. This more closely resembles the current health insurance markets were there are a finite number of coverage levels, platinum, gold, silver and bronze, and a high deductible plan. Let us further suppose that there is free entry of firms into the permitted coverage levels but the government can effectively use subsidies and taxes to control prices.

Policy makers set a finite number of coverage levels, $\vec{\alpha}=\left\{\alpha_{1}=1, \alpha_{2}, \ldots, \alpha_{n}\right\}$, that are targeted to consumer markets given by $\vec{t}=\left\{t_{1}, t_{2},,, t_{n}\right\}$. The next policy instrument is risk adjustment based on observable consumer characteristics. In this model the only public information is the choice of product. It is assumed that the government pays a price subsidy $s_{i}$ to product $\alpha_{i}$. One could use mandates as well, but under the assumption that taxes and subsidies incur the same dead-weight loses, the subsidy case is not only equivalent, but it generates a more convenient objective function. Given a price subsidy $s_{i}$ for product $i$, the welfare cost $(W C)$ for this transfer is given by:

$$
\begin{aligned}
W C_{i} & =\lambda s_{i} q_{i}, \\
& =\lambda s_{i}\left(F\left(t_{i}\right)-F\left(t_{i-1}\right)\right),
\end{aligned}
$$

where $\lambda$ is the marginal cost of using public transfers. This implies that given the consumer price $p_{i}$ and quantity sold of product $\alpha_{i}$, the resulting subsidized profit, $\pi_{i}^{S}$, is:

$$
\begin{aligned}
\pi_{i}^{S} & =\left(p_{i}+s_{i}\right) q_{i}-C_{i}, \\
& =\left(p_{i} q_{i}-C_{i}\right)+s_{i} q_{i} .
\end{aligned}
$$


With perfect competition, one expects $\pi_{i}^{S}=0$, and hence letting $\pi_{i} \leq 0$ be the un-subsidized profit we have:

$$
\begin{aligned}
W C_{i} & =\lambda \times s_{i} q_{i}, \\
& \left.=\lambda \times\left(\pi_{i}^{S}-\pi_{i}\right)\right\}, \\
& =-\lambda \times \min \left\{0, \pi_{i}\right\} .
\end{aligned}
$$

Given that perfect competition is assumed, then in equilibrium firms generate no profits, and hence there is never a motive to tax. It is assumed that there is a welfare cost only when subsidizing unprofitable firms, and one can let market forces deal with cases where firms earn profits. This implies the last line of the welfare cost function. The benefit of this approach is that one does not have to explicitly include the subsidy in the optimal program, but indirectly via firm profits.

Given the products, $\vec{\alpha}$, and markets, $\vec{t}$, then from (12) total profits for market $i$ are:

$$
\pi_{i}(\vec{t}, \vec{\alpha})=p_{i}(\vec{t}, \vec{\alpha})\left(F\left(t_{i}\right)-F\left(t_{i-1}\right)\right)-\alpha_{i} C\left(t_{i-1}, t_{i}\right),
$$

where

$$
C\left(t_{i-1}, t_{i}\right)=\int_{t_{i-1}}^{t_{i}}(1-t) f(t) d t
$$

If profits are negative, $\pi_{i}^{*} \leq 0$, for firms supplying product $q_{i}^{*}$, then the subsidy per unit is defined by:

$$
s_{i}^{*}=-\pi_{i}^{*} / q_{i}^{*}=p_{i}(\vec{t}, \vec{\alpha})-\alpha_{i} A C\left(t_{i-1}, t_{i}\right),
$$

where the last term is the average cost function $A C\left(t_{i-1}, t_{i}\right)=\frac{C\left(t_{i-1}, t_{i}\right)}{\left(F\left(t_{i}\right)-F\left(t_{i-1}\right)\right)}$. If the market share for this product is zero, then the average cost term is replaced by the cost of serving a single type.

Given this, the social planner has two sets of instruments to choose. The first is the number and levels of coverage to offer to the market. To ensure that a solution exists it is assumed that when choosing $n$ products, coverage levels satisfy:

$$
\vec{\alpha} \in \Lambda(n)=\left\{\vec{\alpha} \in[0,1]^{n} \mid \alpha_{1}=1, \alpha_{i} \geq \alpha_{i+1}+\epsilon, i=1, . ., n-1\right\},
$$

for some $\epsilon>0$ that is fixed and independent of $n$. This ensures that there is a finite number of products. The second choice is the market share for each product, $\vec{t} \in \Gamma(n)=\left\{\vec{t} \in[0,1]^{n} \mid 0 \leq t_{1} \leq \ldots \leq t_{n} \leq 1\right\}$. As a matter of convention $t_{0}=0$. With these preliminaries social welfare is defined as follows, followed by the statement of existence:

Definition 12. Given the marginal cost of public funds, $\lambda$, the total welfare of an allocation for $\{\vec{t}, \vec{\alpha}\} \in \Gamma(n) \times \Lambda(n)$ is given by:

$$
T W(\vec{t}, \vec{\alpha}, \lambda)=\sum_{i=1}^{n} W_{i}(\vec{t}, \vec{\alpha})+\lambda \times \min \left\{0, \pi_{i}(\vec{t}, \vec{\alpha})\right\},
$$

where $W_{i}(\vec{t}, \vec{\alpha})=\alpha_{i} \int_{t_{i-1}}^{t_{i}} w(t) f(t) d t$.

Proposition 13. There exists a set of optimal allocations $\Omega^{*}(\lambda)$ such that for all $\left\{\vec{t}^{*}, \vec{\alpha}^{*}\right\} \in \Gamma(n) \times$ $\Lambda(n) \in \Omega^{*}(\lambda)$ :

$$
T W\left(\vec{t}^{*}, \vec{\alpha}^{*}, \lambda\right)=\max _{n \geq 1,\{\vec{t}, \vec{\alpha}\} \in \Gamma(n) \times \Lambda(n)} T W(\vec{t}, \vec{\alpha}, \lambda) .
$$


Proof. The requirement that $\alpha_{i}-\alpha_{i+1} \geq \epsilon$ ensures that the number of products satisfies $n \leq 1 / \epsilon$. For each $n$ the set $\Omega(n)$ is compact, and the function $T W(\vec{t}, \vec{\alpha}, \lambda)$ is the sum of continuous functions, and hence an optimum exist for each $n$. Since $n$ is bounded, then one has a finite number of costs to consider, which in turn ensures the existence of a solution. The continuity of $T W()$ ensures that $\Omega^{*}(\lambda)$ is a compact subset of the feasible allocations.

It turns out that under some natural conditions there is a unique solution that entails offering the high-coverage product, $\alpha_{1}=1$ to consumers $t \in\left[0, t_{1}\right]$. The rest get no insurance. For consumers to self-select into this market, it must be the case that the marginal consumer, $t_{1}$, is indifferent between purchasing insurance and no insurance. Hence the price of product $\alpha_{1}$ is given by:

$$
p_{1}=v\left(t_{1}\right)
$$

The profit function in this case depends only upon $t_{1}$ :

$$
\pi_{1}\left(t_{1}\right)=v\left(t_{1}\right) F\left(t_{1}\right)-\int_{0}^{t_{1}}(1-\tau) f(\tau) d \tau
$$

Total welfare can now be defined in terms of the market share for product $\alpha_{1}$ and social cost of funds, $\lambda$ :

$$
T W\left(t_{1}, \lambda\right)=W\left(t_{1}\right)+\lambda \min \left\{0, \pi_{1}\left(t_{1}\right)\right\},
$$

where $W\left(t_{1}\right)=\int_{0}^{t_{1}} w(t) f(t) d t$ and profits are defined by (42). A necessary condition for this to be a global optimum is that welfare cannot be enhanced by the addition of more products. The example in section 2 shows that in some cases it is optimal to have more than one subsidized good in the market. This occurs when it is optimal to specialize to two or more segments in the population. This is not the case when the problem is concave:

Definition 14. The optimal insurance problem is concave if for $t \in[0,1]$ :

(1) $w^{\prime \prime}(t) \leq 0$.

(2) $\frac{d w(t) f(t)}{d t}<0$.

The first condition is the requirement that welfare be concave in type. This second condition is a smoothness condition on the distribution. For example, a uniform distribution automatically satisfies this condition, while a smoothed version of the two type example would not satisfy this condition. From these conditions it follows immediately that profit function (42) is strictly concave:

$$
\frac{d^{2} \pi_{1}\left(t_{1}\right)}{d t_{1}^{2}}<0, t \in(0,1) .
$$

The requirement that profits be strictly concave with the fact that total welfare is continuous in $t_{1}$, implies there is an optimal market size for product $\alpha_{1}=1$ characterized by

$$
t^{*}(\lambda)=\operatorname{argmax}_{t \in[0,1]} T W\left(t_{1}, \lambda\right) .
$$

Since $\frac{d W\left(t_{1}\right)}{d t_{i}}=w\left(t_{1}\right) f\left(t_{1}\right)>0$ for $t_{1} \in[0,1)$, this implies that when $\lambda=0$, then it is optimal for $t^{*}(0)=1$. 
Next, let $t^{0}$ be the type at which profits are zero, $\pi_{1}\left(t^{0}\right)=0$, and then define:

$$
\lambda^{0}=\frac{w\left(t^{0}\right) f\left(t^{0}\right)}{d \pi_{1}\left(t^{0}\right) / d t} .
$$

For $\lambda>\lambda^{0}$ the strict concavity of profits and differentiating (43) and dividing by $f\left(t_{1}\right)$ implies that for $t_{1}>t^{0}$ :

$$
\frac{\partial T W\left(t_{1}, \lambda\right)}{\partial t_{1}}=w\left(t_{1}\right) f\left(t_{1}\right)-\lambda \frac{d \pi\left(t_{1}, \alpha\right)}{d t_{1}}<0 .
$$

This implies that it is never optimal to set market share $t_{1}>t^{0}$ when $\lambda \geq \lambda^{0}$, and hence $t^{*}(\lambda)=t^{0}$ for $\lambda \geq \lambda^{0}$. For $\lambda \in\left(0, \lambda^{0}\right)$ the optimal market share is now uniquely determined by the first order condition:

$$
w\left(t^{*}(\lambda)\right)-\lambda \frac{d \pi_{1}\left(t^{*}(\lambda)\right)}{d t_{1}}=0 .
$$

The solution is illustrate in figure 6 for the cases in which the cost of public funds satisfies $\lambda_{H}>\lambda^{0}>\lambda_{L}>0$. The function $I_{\pi(t) \leq 0}$ is 1 when profits are non-positive, and zero otherwise. Notice that as the cost of funds rises, the optimal supply falls until we reach the zero profit condition $t^{*}\left(\lambda^{0}\right)=t^{0}$. For $\lambda \geq \lambda^{0}$ the optimal solution entails free entry of the high-coverage products with no subsidy. As the cost of funds falls, we get $t^{*}(\lambda) \rightarrow 1$, and the high-coverage product is sold to all individuals at zero price and subsidy $C(1)=\int_{0}^{1}(1-t) f(t) d t$.

The assumption of strict concavity of the profit function implies a unique social optimum with one product. The next issue is whether or not one should add additional products. From the analysis of the free entry equilibrium, it is certainly possible to add additional products. In particular, suppose one wishes to offer product $\alpha_{2} \in(0,1)$ with some coverage to customers in $\left[t^{*}(\lambda), t_{2}\right]$, where $t_{2}$ is close to $t_{1}$. These are the highest value customers not to be served under a single product allocation. To have types $t_{2}$ indifferent between purchase and no purchase one has to set the price of $\alpha_{2}$ to $\alpha_{2} v\left(t_{2}\right)>0$. In order for customers to continue buying $\alpha_{1}$, the price for $\alpha_{1}$ has to be lowered by $\Delta p=\alpha_{2}\left(v\left(t_{1}\right)-v\left(t_{2}\right)\right)$. Notice that this requires an increase in the subsidy to product $\alpha_{1}$ at a welfare cost of $\lambda \times \Delta p \times F\left(t_{1}\right)>0$.

Locally, this cost is larger than the benefit to the consumers in $\left[t^{*}(\lambda), t_{2}\right]$, and hence it will never be optimal to add the new product. The intuition is quite simple. If it were beneficial to add these consumers, then it would also be optimal to supply to them with the high quality product, which would be achieved by increasing $t_{1}$. However, this is already chosen to be optimal. The example in section 2 is a case in which the welfare optimum entails two products. In that case the distribution of types is bimodal, and so there is a benefit to tailoring products to types when the cost of public funds is sufficiently high. This is no longer the case when the distribution of types is "sufficiently smooth":

Proposition 15. Suppose the optimal insurance problem is concave. Given marginal cost of public funds is $\lambda \geq 0$, let function $t^{*}(\lambda)$ satisfies:

(1) If $\lambda \geq \lambda^{0}$ given by (44) then $t^{*}(\lambda)=t^{0}$, where $\pi_{1}\left(t_{0}\right)=0$.

(2) If $\lambda \in(0,1)$ then $t^{*}(\lambda)$ is the unique solution to $(45)$.

(3) If $\lambda=0$ then $t^{*}(0)=0$. 


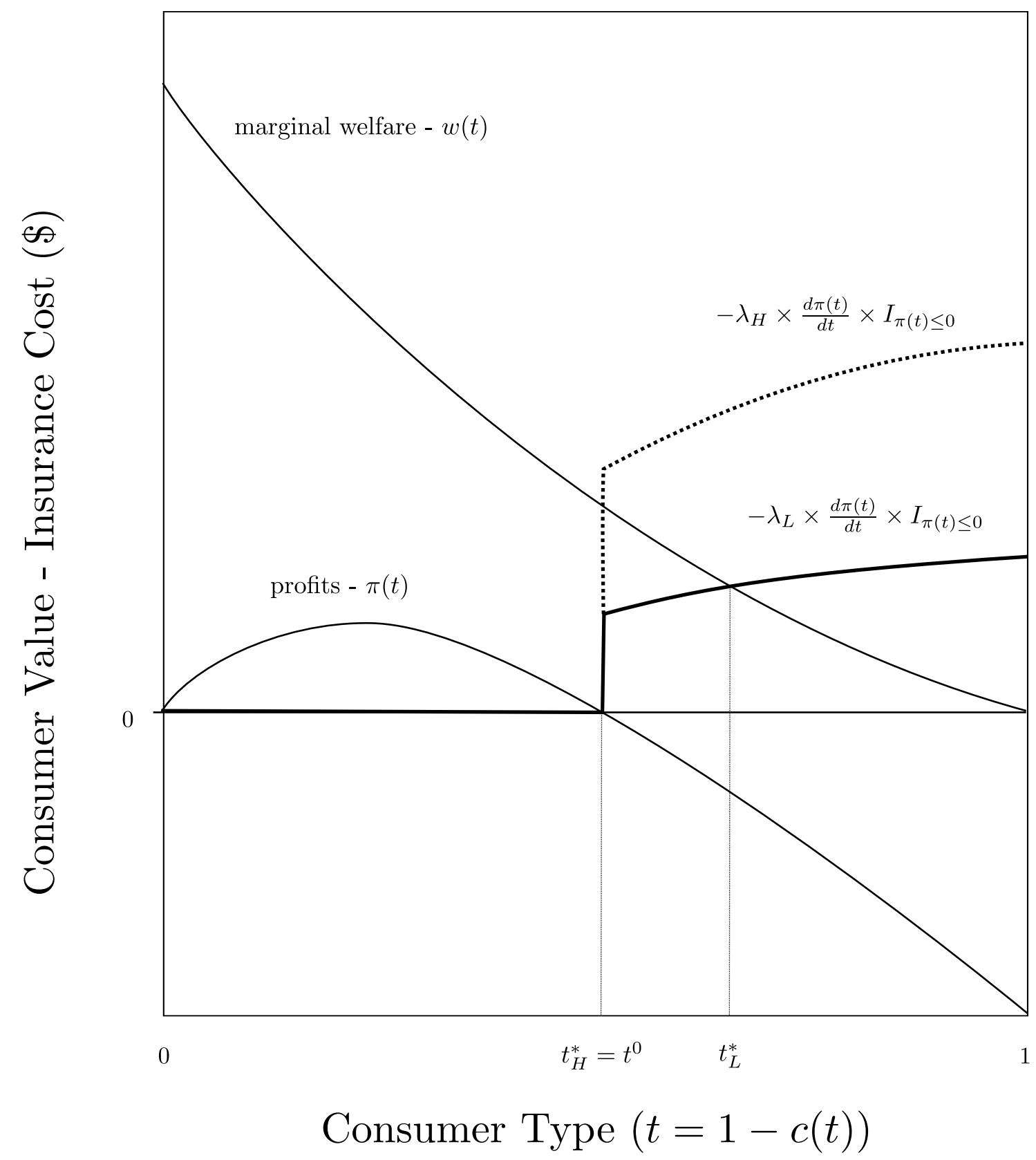

Figure 6. Socially Optimal Product Supply

Then the socially optimal market entails serving customers $t \in\left[0, t^{*}(\lambda)\right]$ with a single high quality product at price:

$$
p^{*}(\lambda)=v\left(t^{*}(\lambda)\right) \text {. }
$$

Details of the proof are in the appendix. This result shows that in this vertically differentiated market it is not optimal to provide diverse coverage in plans. One cannot make any general statements regarding the extent to which the optimal plan falls short of the first best. This depends upon the distribution of cost types given by $f(t)$. If it is multi-modal, then as we saw in the section 
2 example, one may wish to have plans tailored to particular groups. Thus, even in this stripped down model of insurance with vertically differentiated products, the determination of the optimal system is a complex function of the distribution of consumer types.

\section{A Behavioral Optimum}

The results thus far have assumed consumer sovereignty and no externalities to create a wedge between consumer preferences and an individual's true valuation. However, there are many reasons why a person's revealed preference may not be equal to the social value. Young adults may not have the experience to correctly value health insurance. For example, a single traffic accident to an uninsured young adult may result in significant loses that the individual did not anticipate. Also, the parents of children may undervalue insurance for their offspring, or they may face liquidity constraints that make their market valuation be less than the social valuation.

In practice measuring the true social valuation for each family is simply not feasible. An alternative is to suppose that health care has a general social value that is a function of coverage. More precisely, suppose that $B\left(\alpha^{g}\right)$ represents the value of ensuring every citizen in a jurisdiction has universal coverage at the level of $\alpha^{g}$. We can think of this as a national health service. If order for all individuals to participate, then the cost has to be zero to ensure the lowest value person participates. The cost of the system is:

$$
(1+\lambda) \times \alpha^{g} \times C(1),
$$

where $\lambda$ is the marginal social cost of public services raised via the tax system.

In practice, socially provided insurance does not preclude the purchase of insurance from the market. Hence, it is assumed that the policy makers set universal coverage in the presence of a competitive market with free entry. From the results in section 6 we know that such coverage should be unregulated. In such a market, universal health care provides $\alpha^{g}$ coverage, and hence a consumer of type $t$ has some unmet market health demand with private valuation:

$$
\begin{aligned}
v^{m}(t) & =v(t)-v^{g}(t) \\
& =v(t)-\alpha^{g} v(t) \\
& =\left(1-\alpha^{g}\right) v(t) .
\end{aligned}
$$

The cost of supplying these health services that cover all the citizens is similarly:

$$
c^{m}(t)=\left(1-\alpha^{g}\right) c(t)=\left(1-\alpha^{g}\right)(1-t) .
$$

The revelation principle can be used to derive the equilibrium coverage $\alpha^{m}(t)$. Using (26), a consumer of type $t$ who reports $\hat{t}$ gets payoff:

$$
u^{g m}(\hat{t} \mid t)=\alpha^{m}(\hat{t}) v^{m}(t)-\alpha^{m}(\hat{t}) c^{m}(\hat{t})+\alpha^{g} v(t) .
$$

The key assumption here is that the national health plan provides equal access to all its services. This means that there is no adverse selection problem with national health. This payoff can be 
rewritten:

$$
u^{g m}(\hat{t} \mid t)=\left(1-\alpha^{g}\right)\left(\alpha^{m}(\hat{t}) v(t)-\alpha^{m}(\hat{t}) c(\hat{t})\right)+\alpha^{g} v(t) .
$$

The self-selection constraint requires:

$$
\begin{aligned}
0 & =\left.\frac{\partial u^{g m}}{\partial \hat{t}}\right|_{\hat{t}=t}, \\
& =\left.\left(1-\alpha^{g}\right) \frac{\partial\left(\alpha^{m}(\hat{t}) v(t)-\alpha^{m}(\hat{t}) c(\hat{t})\right)}{\partial \hat{t}}\right|_{\hat{t}=t} .
\end{aligned}
$$

The second terms is implies (26), and hence $\alpha^{m}(t)=\alpha(t)$ as derived in section 7. This implies that the welfare from the market participation is given by:

$$
\begin{aligned}
W^{m}\left(\alpha^{g}\right) & =\left(1-\alpha^{g}\right) \int_{0}^{1} \alpha(t) w(t) f(t) d t \\
& =\left(1-\alpha^{g}\right) W^{0},
\end{aligned}
$$

where $W^{0}$ is welfare under the free entry competitive equilibrium. Hence, under a national health plan with private insurance we have that total welfare is given by:

$$
W^{g}\left(\alpha^{g}, \lambda, W^{0}\right)=B\left(\alpha^{g}\right)-(1+\lambda) \times \alpha^{g} \times C(1)+\left(1-\alpha^{g}\right) W^{0} .
$$

For this problem the exogenous parameters are $\lambda$, the marginal cost of public funds, and $W^{0}$, the welfare under a free entry market equilibria. We have shown that at the free entry equilibrium market prices are fixed by the individual valuations. However, note that welfare can vary with the distribution of types, given by $f(t)$, and hence even if cost of funds and valuations are fixed, variation in the distribution of types, say via population characteristics, can lead to different levels of public health provision. The optimal level of public health insurance is given by:

$$
\alpha^{g *}\left(\lambda, W^{0}\right)=\operatorname{argmax}_{\alpha^{g} \in[0,1]} W^{g}\left(\alpha^{g}, \lambda, W^{0}\right) .
$$

The valuation function is assumed to be increasing and concave in coverage, and thus satisfies $B(0)=0, B^{\prime} \geq 0$ and $B^{\prime \prime}<0$. One can also impose some conditions on the slope. At $\alpha^{g}=0$ suppose that the increase in benefit is at least as great as the revealed preferences, $B(0)^{\prime}>W^{*}+C(1)=V^{*}$. Next, it is assumed the full coverage can be viewed as excessive, and hence $B^{\prime}(1)=0$. With these it follows:

Proposition 16. Suppose the benefit function, $B\left(\alpha^{g}\right)$, is twice differentiable, increasing and strictly concave for $\alpha^{g} \in[0,1]$. It is further assumed that it satisfies the boundary conditions, $B(0)=$ $0, B^{\prime}(0)>V^{*}$ and $B^{\prime}(1)=0$. Then there exists an optimal level of public insurance converge, $\alpha^{g *}\left(\lambda, W^{0}\right)$, with the following properties:

(1) For $\lambda \geq \lambda^{m}$, there is no public insurance where

$$
\lambda^{m}=\frac{B^{\prime}(0)-V^{*}}{C(1)}>0 .
$$


(2) For $\lambda \in\left[0, \lambda^{m}\right], \alpha^{g *}\left(\lambda, W^{0}\right)$ is the unique solution to:

$$
B^{\prime}\left(\alpha^{g *}\left(\lambda, W^{0}\right)\right)=(1+\lambda) \times C(1)+W^{0},
$$

and it is a decreasing function of $\lambda$ and $W^{0}$.

Thus, the coverage by the public sector falls with the cost of public funds, and is zero when these are sufficiently high. Similarly, the higher the level of health services supplied by the free market equilibrium, the smaller the size of the public health sector. The assumption that $B^{\prime}(1)=0$ implies that, in this case, it is never optimal to have pure public provision, even when the cost of funds is zero $(\lambda=0)$.

\section{Discussion}

This paper introduces a perfectly competitive model of a vertically differentiated market with endogenous product choice. The model can be viewed as a reduced form representation of an insurance market. It is designed to capture the essential features of a market with adverse selection, while at the same time simple enough to allow for welfare analysis. One of the innovations is to view the cost of funds as a parameter. This allows us to ask how variations in beliefs regarding the cost of government intervention can lead to quite different policy implications, a result that is consistent with the large observed variation in policy positions on how health care should be managed in the United States.

The main technical contribution begins with Azevedo and Gottlieb (2017) who build a perfectly competitive model with free entry of products. Their model shows that such an equilibrium exists and has features that are consistent with the data. These results show that one does not need to use imperfect competition models (Ho and Lee (2017)), or price setting models (see Einav et al. (2010)) to capture some of the salient features of this market. However, as Azevedo and Gottlieb (2017) observe, their model is not easily amenable for welfare analysis.

This paper provides a solution to this problem building upon the results of Marone and Sabety (2020) who show that the US health care model is well characterized by vertical differentiation. The starting point for the analysis is the assumption that the market is mainly vertically differentiated via the level of insurance coverage. When consumer willingness to pay is positively correlated with the cost of servicing an individual, then, using the revelation principle, it is shown in section 4 that there is a one-to-one correspondence between prices and quantities. This allows one to follow Novshek and Sonnenschein (1978) to build a model of perfect competition in quantity space.

This allows one to specify an explicit dynamic model, which not only proves the existence of an equilibrium under very weak conditions, it could be used in future work for some explicit modeling of dynamic adjust in these markets. The requirement that equilibria are stable is used in section 6 to make predictions on the comparative static effects of policy changes.

The introduction of free entry of vertically differentiated products provides some insights into the death spiral in markets with adverse selection. The example in section 2 shows that rather than causing products to leave, adverse selection mainly causes low cost individuals to consume lower quality products than they would otherwise. An interesting feature of the free entry equilibrium 
is that the adverse selection effects completely fixes prices, and hence implies that markets with adverse selection respond poorly to supply and demand shocks.

The analysis is carried assuming the consumer characteristics vary in one dimension only - the cost providing the consumer with full insurance. The analysis can be applied to any well defined pool of individuals. In particular, the welfare analysis implies that employers who can cross-subsidized employee costs, should only supply one type of coverage. ${ }^{9}$ The example in section 2 shows that with consumer types characterized by a bimodal distribution, thne two plans may be optimal. This is consistent with the observation that larger firms, with more diverse workforces, may offer more choice. In the case of market provided plans, in the absence of regulated quality, and with a high cost of public funds, then a free entry competitive equilibrium with many coverage levels may be efficient.

A related insight is that the appropriate policy interventions are sensitive to the underlying distribution of costs. Much of the empirical work in this literature focuses upon the marginal effects of policy changes. However, as illustrated in Sections 2 and 8, the appropriate policy may depend upon non-local features of the distribution of costs and willingness to pay.

The positive analysis of behavior depends upon individual willingness to pay. There is quite a bit of evidence that individuals in these markets are not always able to process information efficiently (Handel (2013); Abaluck and Gruber (2016); Handel et al. (2019)). For example, it is not clear that children, via their parents, are getting optimal insurance coverage (Currie and Gruber (1996a,b)). Section 10 uses the model to explore the design of insurance markets when the social return to universal health care is greater than the private return. In that case, the optimal system is one with some universal coverage combined with a private system. As before, the level of coverage is a function of the perceived social cost of public funds, with a larger and more generous public system when the social cost of public funds is lower.

Given the simplicity of the model there are many possible extensions. These may include empirically implementing the equilibrium in quantity space and possibly trying to derive the imputed cost of public funds from the data. Also, the model is for a market where all the consumers are observationally equivalent. These techniques can be naturally extended to situations where policies can depend upon observed features of individuals (Glazer and McGuire (2000); Ellis (2008); Layton et al. (2018))

\section{REFERENCES}

Abaluck, J. and J. Gruber (2016, August). Evolving choice inconsistencies in choice of prescription drug insurance. American Economic Review 106(8), 2145-84.

Akerlof, G. A. (1970). The market for "lemons": Quality uncertainty and the market mechanism. The Quarterly Journal of Economics 84(3), 488-500.

Azevedo, E. M. and D. Gottlieb (2017). Perfect competition in markets with adverse selection. Econometrica 85(1), 67-105.

\footnotetext{
${ }^{9}$ A recent survey, https://www.kff .org/report-section/ehbs-2019-section-4-types-of-plans-offered/, finds that more than $70 \%$ of employers offer only one plan, while there is a tendency for larger firms to offer two and sometimes three choices.
} 
Caillaud, B., R. Guesnerie, P. Rey, and J. Tirole (1988). Government intervention in production and incentives theory: A review of recent contributions. The RAND Journal of Economics 19(1), $1-26$.

Currie, J. and J. Gruber (1996a, May). Health insurance eligibility, utilization of medical care, and child health. Quarterly Journal of Economics 111(2), 431-466.

Currie, J. and J. Gruber (1996b, Dec). Saving babies: the efficacy and cost of recent changes in the medicaid eligibility of pregnant women. Journal of Political Economy 104(6), 1263-1296.

Cutler, D. M. and S. J. Reber $(1998,05)$. Paying for health insurance: The trade-off between competition and adverse selection. The Quarterly Journal of Economics 113(2), 433-466.

Cutler, D. M. and R. J. Zeckhauser (1998, January). Adverse Selection in Health Insurance, pp. 1-32. MIT Press.

Einav, L., A. Finkelstein, and M. R. Cullen (2010). Estimating welfare in insurance markets using variation in prices. Quarterly Journal of Economics 125(3), 877-921.

Einav, L., A. Finkelstein, and J. Levin (2010). Beyond Testing: Empirical Models of Insurance Markets, Volume 2 of Annual Review of Economics, pp. 311-336. Palo Alto: Annual Reviews.

Einav, L., A. Finkelstein, and P. Schrimpf (2010). Optimal mandates and the welfare cost of asymmetric information: Evidence from the uk annuity market. Econometrica 78(3), 1031-1092.

Ellis, R. P. (2008). Financing Health Care. Volume 2 of Health Care and Disease Management., Chapter Risk adjustment in health care markets: concepts and applications., pp. 177-222. Edmonton, Canada: John Wiley \& Sons.

Frean, M., J. Gruber, and B. D. Sommers (2017). Premium subsidies, the mandate, and medicaid expansion: Coverage effects of the affordable care act. Journal of Health Economics 53, 72 - 86.

Gabszewicz, J. and J. Thisse (1979). Price-competition, quality and income disparities. Journal of Economic Theory 20(3), 340-359.

Geruso, M. and T. J. Layton (2017). Selection in health insurance markets and its policy remedies. Journal of Economic Perspectives 31(4), 23-50.

Geruso, M., T. J. Layton, G. McCormack, and M. Shepard (2019, September). The two margin problem in insurance markets. Working Paper 26288, National Bureau of Economic Research.

Glazer, J. and T. G. McGuire (2000). Optimal risk adjustment in markets with adverse selection: An application to managed care. The American Economic Review 90(4), 1055-1071.

Hackmann, M. B., J. T. Kolstad, and A. E. Kowalski (2015). Adverse selection and an individual mandate: When theory meets practice. American Economic Review 105(3), 1030-1066.

Handel, B., I. Hendel, and M. D. Whinston (2015). Equilibria in health exchanges: Adverse selection versus reclassification risk. Econometrica 83(4), 1261-1313.

Handel, B. R. (2013). Adverse selection and inertia in health insurance markets: When nudging hurts. American Economic Review 103(7), 2643-2682.

Handel, B. R., J. T. Kolstad, and J. Spinnewijn (2019). Information frictions and adverse selection: Policy interventions in health insurance markets. The Review of Economics and Statistics 101(2), 326-340. 
Hirsch, M. W. and S. Smale (1974). Differentiable Equations, Dynamical Systems, and Linear Algebra. San Diego, CA: Academic Press.

Ho, K. and R. S. Lee (2017, March). Insurer competition in health care markets. Econometrica $85(2), 379-417$.

Klein, B. and K. Leffler (1981). The role of market forces in assuring contractual performance. Journal of Political Economy 89, 615-641.

Laffont, J.-J. and J. Tirole (1986, June). Using cost observation to regulate firms. Journal of Political Economy 94(3), 614-641.

Layton, T. J. (2017). Imperfect risk adjustment, risk preferences, and sorting in competitive health insurance markets. Journal of Health Economics 56, 259-280.

Layton, T. J., T. G. McGuire, and R. C. van Kleef (2018). Deriving risk adjustment payment weights to maximize efficiency of health insurance markets. Journal of Health Economics 61, 93-110.

MacLeod, W. B. (1985). On adjustment costs and the stability of equilibria. The Review of Economic Studies 52(4), pp.575-591.

Marone, V. R. and A. Sabety (2020, June). Should there be vertical choice in health insurance markets. Northwestern University.

Myerson, R. (1979, January). Incentive compatibility and the bargaining problem. Econometrica $47(1), 61-74$.

Novshek, W. and H. Sonnenschein (1978). Cournot and Walras equilibrium. Journal of Economic Theory 19(2), $223-266$.

Riley, J. G. (1979). Informational equilibrium. Econometrica 47(2), 331-359.

Rothschild, M. and J. E. Stiglitz (1976). Equilibrium in competitive insurance markets: An essay on the economics of imperfect information. Quarterly Journal of Economics 90(4), 630-49.

Scholtes, S. (2012). Introduction of Piecewise Differentiable Equations. Springer.

\section{Appendix A. Appendix}

A.1. Proof of Proposition 7. Let $m_{i j}=\frac{\partial m_{i}\left(t_{1}, t_{2}\right)}{\partial t_{j}}$ be the effect of type $t_{j}$ on the mark-up for product $\alpha_{i}$. At a competitive equilibrium $m_{1}=m_{2}=-p^{M}$. Differentiating with respect to $p^{M}$ we get:

Solving for the derivatives we get:

$$
\left[\begin{array}{ll}
m_{11} & m_{12} \\
m_{21} & m_{22}
\end{array}\right]\left[\begin{array}{c}
\frac{d t_{1}}{d p^{M}} \\
\frac{d t_{2}}{d p^{M}}
\end{array}\right]=\left[\begin{array}{l}
-1 \\
-1
\end{array}\right]
$$

$$
\begin{aligned}
{\left[\begin{array}{c}
\frac{d t_{1}}{d p^{M}} \\
\frac{d t_{2}}{d p^{M}}
\end{array}\right] } & =\frac{1}{m_{11} m_{22}-m_{21} m_{12}}\left[\begin{array}{cc}
m_{22} & -m_{12} \\
-m_{21} & m_{11}
\end{array}\right]\left[\begin{array}{l}
-1 \\
-1
\end{array}\right], \\
& =\frac{1}{m_{11} m_{22}-m_{21} m_{12}}\left[\begin{array}{c}
-m_{22}+m_{12} \\
m_{21}-m_{11}
\end{array}\right]
\end{aligned}
$$


The assumption that the equilibrium is stable implies $m_{11}, m_{22}<0$. Next, we have:

$$
\begin{aligned}
& m_{12}=\alpha_{2} v^{\prime}\left(t_{2}\right)<0, \\
& m_{21}=-\alpha_{2} \frac{\partial A C_{2}\left(t_{1}, t_{2}\right)}{\partial t_{1}}>0 .
\end{aligned}
$$

This implies that the determinant, $m_{11} m_{22}-m_{21} m_{12}$, in the denominator is strictly positive. This also implies $m_{21}-m_{11}>0$. Next, observe that:

$$
\begin{aligned}
-m_{22}+m_{12} & =-\alpha_{2}\left(v^{\prime}\left(t_{2}\right)-\frac{\partial A C_{2}\left(t_{1}, t_{2}\right)}{\partial t_{2}}\right)+\alpha_{2} v^{\prime}\left(t_{2}\right) \\
& =\alpha_{2} \frac{\partial A C_{2}\left(t_{1}, t_{2}\right)}{\partial t_{2}}<0 .
\end{aligned}
$$

Thus $\frac{d t_{1}}{d p^{M}}<0$ and $\frac{d t_{2}}{d p^{M}}>0$.

A.2. Proof of Proposition 8. To show this proposition observe:

$$
W\left(t_{1}, t_{0}\right)=\alpha_{1} \int_{0}^{t_{1}} w(t) f(t) d t+\alpha_{2} \int_{t_{1}}^{t_{2}} w(t) f(t) d t
$$

Thus we have:

$$
\begin{aligned}
\frac{d W}{d p^{M}} & =\left(\alpha_{1} w\left(t_{1}\right) f\left(t_{1}\right)-\alpha_{2} w\left(t_{1}\right) f\left(t_{1}\right)\right) \frac{d t_{1}}{d p^{M}}, \\
& +\left(\alpha_{2} w\left(t_{2}\right) f\left(t_{2}\right)\right) \frac{d t_{2}}{d p^{M}} .
\end{aligned}
$$

Since the demand for product $\alpha_{1}$ satisfies $q_{1}=F\left(t_{1}\right)$, then $\frac{d q_{1}}{d p^{M}}=f\left(t_{1}\right) \frac{d t_{1}}{d p^{M}}$. Similarly, total

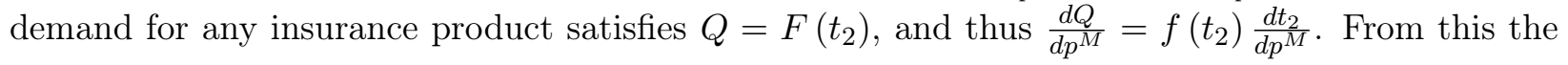
effect of the insurance mandate on welfare is given by:

$$
\frac{d W}{d p^{M}}=\delta_{1} w\left(t_{1}\right) \frac{d q_{1}}{d p^{M}}+\alpha_{2} w\left(t_{2}\right) \frac{d Q}{d p^{M}}
$$

A.3. Solving (28). Observe that (28) can be rewritten in the form:

$$
\frac{d \log (\alpha(t))}{d t}=\frac{-1}{w(t)} \equiv h(t)<0 .
$$

Consider the equilibrium with the highest coverage product in the market, which in turn implies $\alpha(0)=1$. From this we get a unique solution:

$$
\begin{aligned}
\log (\alpha(t)) & =\int_{0}^{t} h(\tau) d \tau \\
\alpha(t) & =\exp \left(\int_{0}^{t} h(\tau) d \tau\right) .
\end{aligned}
$$

Notice that $\lim _{t \rightarrow 1} h(t)=-\infty$ then we get $\lim _{t \rightarrow 1} \alpha(t)=0$. Also, $\alpha^{\prime}(t)=h^{\prime}(t) \alpha(t)$. 
Next we check if the second order condition for the consumer is satisfied:

$$
\begin{aligned}
d u(\hat{t} \mid t) / d \hat{t} & =\alpha^{\prime}(\hat{t})(v(t)+\hat{t}-1)+\alpha(\hat{t})=0, \\
d^{2} u(\hat{t} \mid t) / d \hat{t} d \hat{t} & =\alpha^{\prime \prime}(\hat{t})(v(t)+\hat{t}-1)+2 \alpha^{\prime}(\hat{t}) .
\end{aligned}
$$

Thus at $\hat{t}=t$ we have:

$$
\begin{aligned}
d^{2} u(\hat{t} \mid t) /\left.d \hat{t} d \hat{t}\right|_{\hat{t}=t} & =\alpha^{\prime \prime}(t) w(t)+2 \alpha^{\prime}(t) \\
& =-\alpha^{\prime \prime}(t) / h(t)+2 \alpha^{\prime}(t)
\end{aligned}
$$

Observe that from (46) with $\hat{t}=t$ :

$$
\alpha^{\prime \prime}(t)=h(t) \alpha^{\prime}(t)+h^{\prime}(t) \alpha(t) .
$$

We now plug into the expression for the second order condition to get:

$$
\begin{aligned}
d^{2} u(\hat{t} \mid t) /\left.d \hat{t} d \hat{t}\right|_{\hat{t}=t} & =-\alpha^{\prime}(t)+h^{\prime}(t) \alpha(t) w(t)+2 h^{\prime}(t) \alpha(t), \\
& =-h^{\prime}(t) \alpha(t)+h^{\prime}(t) \alpha(t) w(t)+2 h^{\prime}(t) \alpha(t), \\
& =h^{\prime}(t) \alpha(t)(\alpha(t)+w(t)) .
\end{aligned}
$$

Since $w^{\prime}(t)<0$ then $h(t), h^{\prime}(t)<0$, and the second order condition is satisfied.

Since the firms are producing "zero output" at price equal marginal costs, then the Hessian with respect to quantity is zero and one has a weakly stable equilibrium.

A.4. Proof of Proposition (15). It is efficient for all individuals to have full coverage, and hence it follows immediately that when $\lambda=0, t^{*}(0)=0$, insurance is provided free of cost $(v(0)=0)$, and the subsidy is equal to the average cost (maximum demand is normalized at $1=F(1)$ ):

$$
s^{*}=C(1)=\int_{0}^{t}(1-t) f(t) d t .
$$

When $\lambda \in\left(0, \lambda^{0}\right)$ then using the fact that $v(t)=w(t)+(1-t)$ the first order condition for (43) is given by:

$$
F O\left(t^{*}\right) \equiv w\left(t^{*}\right) f\left(t^{*}\right)+\lambda\left[w\left(t^{*}\right) f\left(t^{*}\right)+v^{\prime}\left(t^{*}\right) F\left(t^{*}\right)\right]=0 .
$$

The strict concavity of profits imply that $t^{*}$ is unique and it solves:

$$
\frac{v^{\prime}\left(t^{*}\right) F\left(t^{*}\right)}{w\left(t^{*}\right) f\left(t^{*}\right)}=\frac{1+\lambda}{\lambda}
$$

This next step is to show that adding a new product $\alpha_{2} \in(0,1)$ cannot enhance welfare. Given adverse selection, adding a new product necessarily means serving new customers $t \in\left[t_{1}^{*}, t_{2}\right]$. To have customers self-select into this group requires decreasing the price for product $\alpha_{1}$ so that customer $t_{1}^{*}$ is indifferent between $\alpha_{1}$ and $\alpha_{2}$, which in turn requires an increase in the subsidy to product $\alpha_{1}$ of size $\alpha_{2}\left(v\left(t_{1}^{*}\right)-v\left(t_{2}\right)\right)$. Consider first the case in which $t_{2}$ is sufficiently close to $t_{1}^{*}$ such that profits are strictly positive (since $v\left(t^{*}\right)>c\left(t^{*}\right)$. Thus there is no subsidy for product $\alpha_{2}$ and we 
have:

$$
\begin{aligned}
W\left(t_{1}^{*}, t_{2}\right) & =W\left(t_{1}^{*}\right)-\lambda \alpha_{2}\left(v\left(t_{1}^{*}\right)-v\left(t_{2}\right)\right) F\left(t_{1}^{*}\right) \\
& +\alpha_{2} \int_{t_{1}^{*}}^{t_{2}} w(t) f(t) d t .
\end{aligned}
$$

From this we get:

$$
F O_{2}\left(t_{1}^{*}, t_{2}\right)=\frac{\partial W\left(t_{1}^{*}, t_{2}\right)}{\partial t_{2}}=\alpha_{2}\left(w\left(t_{2}\right) f\left(t_{2}\right)+\lambda\left(w^{\prime}\left(t_{2}\right)-1\right) F\left(t_{1}^{*}\right)\right) .
$$

Notice that for $t_{2}$ close to $t_{1}^{*}$ we have:

$$
\alpha_{2} F\left(t_{1}^{*}\right)-F O_{2}\left(t_{1}^{*}, t_{2}\right) \cong \alpha_{2} \lambda w\left(t^{*}\right) f\left(t^{*}\right)>0
$$

Hence locally, it is optimal to make $t_{2}$ as small as possible. The reason is that the entry of product $\alpha_{2}$ requires a payment to all customers who buy $\alpha_{1}$ of size $\alpha_{2}\left(v\left(t_{1}^{*}\right)-v\left(t_{2}\right)\right) F\left(t_{1}^{*}\right)$. However, since profits are positive for the entrant these do not enter the social welfare function. In contrast, expanding product $\alpha_{1}$ has a positive benefit the marginal profits are positive, even though average profits are negative.

The final step is to ensure that this is a global optimum. If we ignore the cost associated with the subsidy, then a sufficient condition for $t_{2}=t_{1}^{*}$ to be optimal is for $t \in\left[t^{*}(\lambda), 1\right]$ :

$$
\alpha_{2}\left(w\left(t_{2}\right) f\left(t_{2}\right)+\lambda v^{\prime}\left(t_{2}\right) F\left(t^{*}(\lambda)\right)\right) \leq 0 .
$$

The first order condition implies:

$$
w\left(t^{*}(\lambda)\right) f\left(t^{*}(\lambda)\right)+\lambda v^{\prime}\left(t^{*}(\lambda)\right) F\left(t^{*}(\lambda)\right)<0 .
$$

The concavity of the optimal insurance problem implies that (48) is a deceasing function of $t_{2}$, and we are done.

Columbia University, Department of Economics, 420 West 118th, MC 3308, New York, Ny 100277296, USA

Email address: bentley.macleod@columbia.edu 